\title{
Generating Artificial Sensations with Spinal Cord Stimulation in Primates and Rodents
}

\author{
Amol P. Yadav ${ }^{1-4}$, Shuangyan Li $i^{3,11,12}$, Max O. Krucoff ${ }^{1,8}$, Mikhail A. Lebedev' ${ }^{2,9,10}$, Muhammad M.
} Abd-El-Barr ${ }^{1}$, Miguel A.L. Nicolelis ${ }^{1-7}$

${ }^{1}$ Department of Neurosurgery, ${ }^{2}$ Center for Neuroengineering, ${ }^{3}$ Department of Neurobiology, ${ }^{4}$ Department of Biomedical Engineering, ${ }^{5}$ Department of Psychology and Neuroscience, ${ }^{6}$ Department of Neurology, Duke University, Durham, NC 27710, ${ }^{7}$ Edmond and Lily Safra International Institute of Neuroscience, Natal, Brazil 59066060, ${ }^{8}$ Department of Neurosurgery, Medical College of Wisconsin, Milwaukee, WI 53226, ${ }^{9}$ Center for Bioelectric Interfaces of the Institute for Cognitive Neuroscience, National Research University Higher School of Economics, Moscow, Russia 101000, ${ }^{10}$ Department of Information and Internet Technologies of Digital Health Institute, I.M. Sechenov First Moscow State Medical University, Moscow, Russia 119146, ${ }^{11}$ State Key Laboratory of Reliability and Intelligence of Electrical Equipment, School of Electrical Engineering, ${ }^{12}$ Tianjin Key Laboratory Bioelectromagnetic Technology and Intelligent Health, Hebei University of Technology, Tianjin 300130, P.R.China

\section{Corresponding Author:}

Amol P. Yadav, Ph.D.

Department of Neurosurgery

Duke University,

23 Box 103905, Durham, NC 27710

4 amol.yadav@duke.edu 


\section{Abstract}

27 For patients who have lost sensory function due to a neurological injury such as spinal cord injury

28 (SCI), stroke, or amputation, spinal cord stimulation (SCS) may provide a mechanism for restoring

29 somatic sensations via an intuitive, non-visual pathway. Inspired by this vision, here we trained

30 rhesus monkeys and rats to detect and discriminate patterns of epidural SCS. Thereafter, we constructed psychometric curves describing the relationship between different SCS parameters and the animal's ability to detect SCS and/or changes in its characteristics. We found that the stimulus detection threshold decreased with higher frequency, longer pulse-width, and increasing duration of SCS. Moreover, we found that monkeys were able to discriminate temporally- and spatially-varying patterns (i.e. variations in frequency and location) of SCS delivered through multiple electrodes. Additionally, sensory discrimination of SCS-induced sensations in rats obeyed Weber's law of just noticeable differences. These findings suggest that by varying SCS intensity, temporal pattern, and location different sensory experiences can be evoked. As such, we posit that SCS can provide intuitive sensory feedback in neuroprosthetic devices. 
Lack of sensory feedback from a brain-controlled actuator or prosthetic device is a major hindrance to successful integration of the neuroprosthesis in activities of daily life and rehabilitative protocols (1-3). The somatosensory cortex (S1) and thalamus have been proposed as potential targets for neurostimulation that could produce naturalistic somatosensory percepts (4-10). However, stimulating these brain areas requires surgical implantation of deep intracranial electrodes - a procedure associated with significant risks. While peripheral nerve stimulation provides a less invasive alternative, sensations evoked with this method are highly localized, and thus limited in their applicability as a general-purpose sensory input pathway to the brain (11-13). Previously, our group demonstrated that electrical stimulation of the dorsal surface of the spinal cord can be used to transmit sensory information to the brain or between multiple brains in rodents (14). Building on this previous work, here we explored whether rats and nonhuman primates can learn to detect and discriminate artificial sensations generated with dorsal thoracic epidural spinal cord stimulation (SCS). Understanding the psychophysical relationship between SCS parameters and the ability to detect sensations is critical for the development of novel neuroprosthetic devices that restore function to people with sensory disabilities. We examined how sensory discrimination changes when SCS parameters are varied in both rodent and primate models, and we asked whether animals can learn to discriminate sensations generated by SCS patterns that vary in

66 frequency and spatial location. After training the animals to discriminate SCS patterns, we

67 determined whether artificial sensations evoked by SCS of variable frequency follow Weber's law of just noticeable differences (JND) - a critical property defining sensory discrimination.

\section{Results}

We implanted three rhesus monkeys with percutaneous epidural SCS electrodes at the dorsal

71 thoracic spinal level and trained them to perform a two-alternative forced choice task (2AFC) using

72 a joystick-controlled cursor (Figure 1a, Supplementary Figures 1b, 1c, and 1d). In a typical 
a
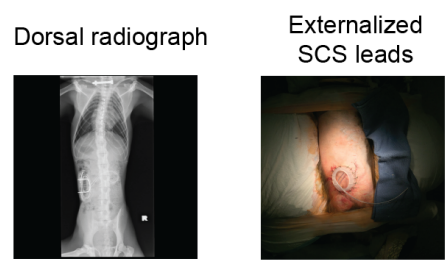

C

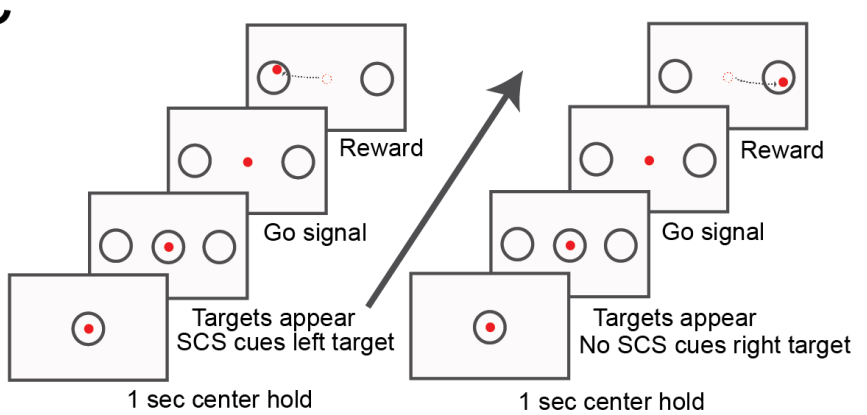

SCS leads inside plastic housing

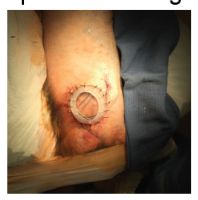

b

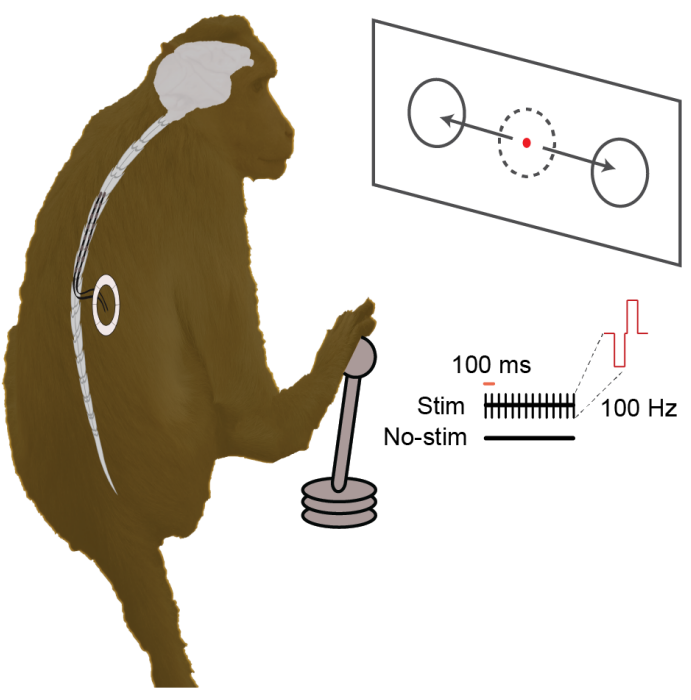

Figure 1: Surgery and experimental task setup. a) We implanted three non-human primates (rhesus monkeys) with SCS percutaneous leads over the T6-T10 dorsal epidural surface of the spinal cord. Leads were externalized from the lower back area and secured inside a custom plastic housing. Leads were manually accessed by the experimenter for daily training and connected to a custom pulse stimulator. b) Monkeys were seated in a primate chair in front of a computer monitor with access to a hand-controlled joystick. They participated in a two-alternative forced choice task (2AFC) by moving the joystick controlling a cursor on the screen in order to receive a juice reward. c) On each trial, monkeys had to hold the cursor inside the center circle for $1 \mathrm{sec}$. After that, targets appeared on the left and right side of the center. Monkeys were presented with 'SCS-ON' (biphasic, $100 \mathrm{~Hz}, 200 \mu \mathrm{s}, 1 \mathrm{sec}$ ) cue or 'SCS-OFF' cue when the targets appeared. After a brief, variable hold period (100-1000 ms), the center circle disappeared which indicated them to move the joystick. Monkeys had to move the cursor inside the left target on 'SCS-ON' trials and inside the right target on 'SCS-OFF' trials. Correct response resulted in juice reward. In the SCS discrimination task, stimulation was delivered at $200 \mu \mathrm{s}$ for $1 \mathrm{sec}$. Monkeys had to select left target for 100 $\mathrm{Hz}$ stimulus and right target for $200 \mathrm{~Hz}$ stimulus in the frequency discrimination task. For spatial discrimination task, monkeys had to choose left target when stimulation was delivered at electrode pair 1 and right target for stimulation at electrode pair 2. 
91 experimental session, a monkey was seated in a chair in front of a monitor that displayed task-

92 related cues. The animals moved a hand-held joystick to control a cursor on a screen (Figure 1b).

93 A typical trial consisted of a brief $(300-500 \mathrm{~ms})$ center hold period after which two targets

94 appeared. After a brief preparatory period (250 - $1000 \mathrm{~ms})$ during which a trial cue was presented,

95 the monkeys had to move the cursor into one of the targets to obtain a juice reward. Monkeys

96 were initially trained to identify the correct target using a visual cue; however, during the

97 experimental sessions, no visual cues were presented, and they selected a target by interpreting

SCS cues alone. In the detection task, monkeys had to select the left target if SCS was delivered

during the preparatory period and right target if no SCS was delivered (Figure 1c). In the

for electrode pair 2 (spatial discrimination).

Monkeys $\mathrm{M}, \mathrm{O}$, and $\mathrm{K}$ learned to detect SCS-induced sensory percepts evoked using

\section{Electrode thresholds and electrode mapping}

111 Once the monkeys learned to detect SCS sensations, we used psychometric analysis to 112 determine the detection thresholds for different electrode combinations (Figure 2b). We observed 113 that the detection thresholds varied from $315.6 \mu \mathrm{A}$ to $340 \mu \mathrm{A}$ for monkey $\mathrm{O}$ and $197 \mu \mathrm{A}$ to $748 \mu \mathrm{A}$ 

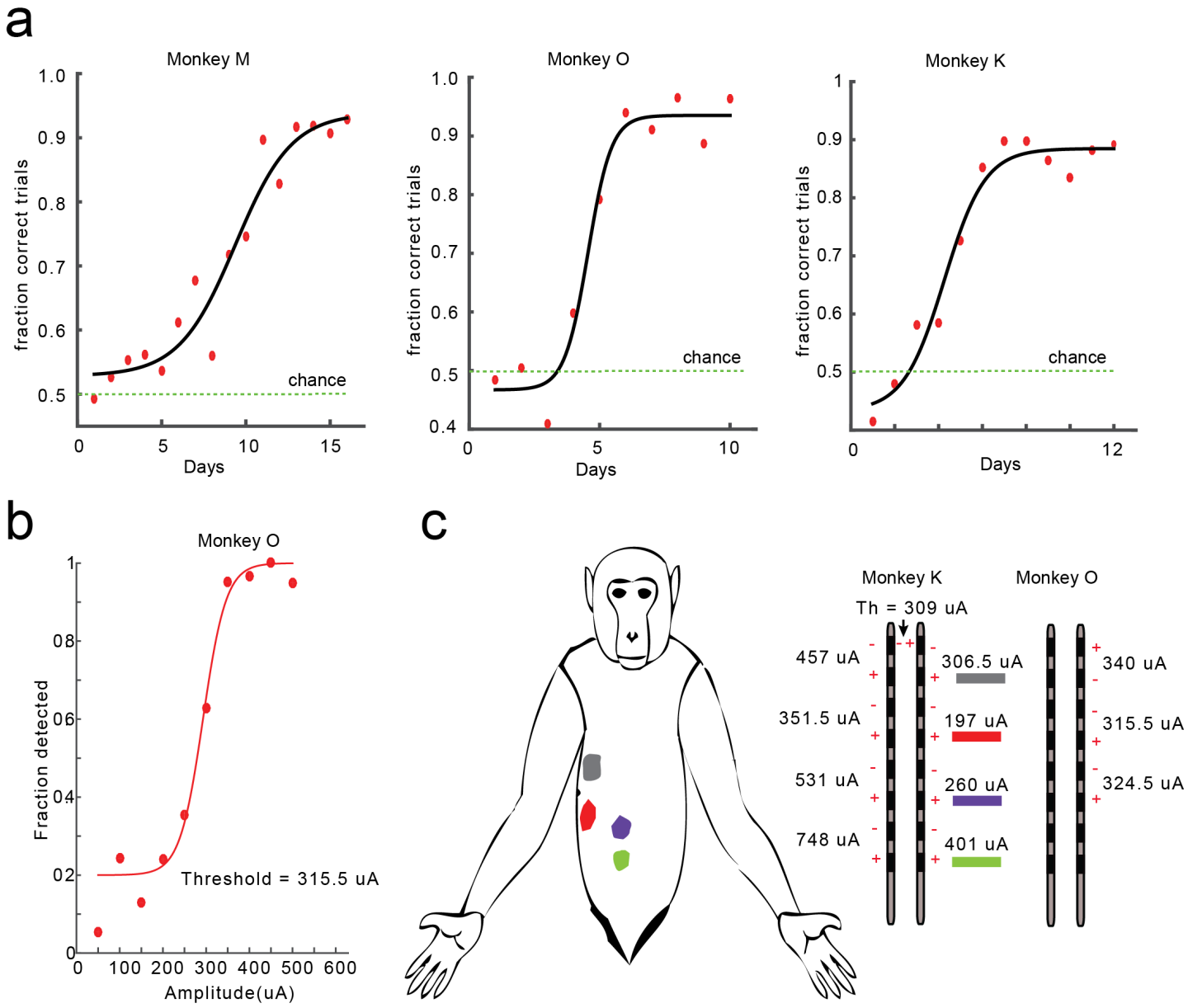

Figure 2: Monkeys learned to detect SCS stimuli. a) Learning curves (sigmoidal fits) for monkeys $\mathrm{M}, \mathrm{O}$, and K showing behavioral performance (fraction correct trials) as a function of training days. b) Psychometric function showing fraction trials detected as a function of stimulation amplitude in monkey $\mathrm{O}$. Detection threshold is defined as amplitude at which monkeys achieved $75 \%$ performance on detection task. c)

121 Mapping of bipolar electrode pairs on monkey K's body where stimulation on right-side electrode at 122 suprathreshold amplitude elicited minor muscle twitches or skin flutter (color coded by electrode pairs and corresponding sensory thresholds shown on right). Monkey body shape is adapted from (15). 
127

128

129

130

131

132

muscle twitches or skin flutter. We observed that muscle twitches/skin flutter were elicited in the trunk and abdomen area only at suprathreshold values but not at sensory threshold values (Figure 2c). We also noted that in both monkeys $\mathrm{K}$ and $\mathrm{O}$ experimentally determined sensory thresholds were always lower than the observed motor thresholds for each cathode-anode electrode pair (Supplementary Figure 3b).

\section{Sensitivity to detection of sensory percepts in primates}

Thereafter, we investigated the psychophysical relationship between stimulation parameters and detection of sensory percepts by varying stimulation amplitudes along with stimulation frequency, pulse-width, or duration of stimulation while keeping the other two parameters constant.

We varied amplitude from $50 \mu \mathrm{A}$ to $800 \mu \mathrm{A}$ for pulse-widths of $50 \mu \mathrm{s}, 100 \mu \mathrm{s}, 200 \mu \mathrm{s}$, and $400 \mu \mathrm{s}$ for monkey $\mathrm{K}$, and pulse-widths of $100 \mu \mathrm{s}, 200 \mu \mathrm{s}$, and $400 \mu \mathrm{s}$ for monkey O. Frequency and duration of stimulation were held constant (Figures 3a, 3e, and Supplementary Figure 2a). We observed that stimulus detection threshold significantly decreased with increasing stimulation pulse-width ( $p<0.05$, repeated measures one-way ANOVA) for both animals (Figure $3 \mathrm{~h}$ ).

We varied amplitude from $50 \mu \mathrm{A}$ to $800 \mu \mathrm{A}$ for frequencies of $10 \mathrm{~Hz}, 20 \mathrm{~Hz}, 50 \mathrm{~Hz}, 100 \mathrm{~Hz}, 200$ $\mathrm{Hz}$, and $500 \mathrm{~Hz}$ for monkey K, and frequencies of $20 \mathrm{~Hz}, 50 \mathrm{~Hz}, 100 \mathrm{~Hz}, 200 \mathrm{~Hz}$, and $500 \mathrm{~Hz}$ for monkey $\mathrm{O}$ while keeping pulse-width and duration of stimulation constant (Figures $3 \mathrm{~b}$, 3f, and Supplementary Figure 2b). We observed that stimulation detection threshold significantly decreased with increasing stimulation frequency $(p<0.05$, repeated measures one-way ANOVA) for both animals (Figure 3i).

We varied amplitude from $50 \mu \mathrm{A}$ to $600 \mu \mathrm{A}$ for duration of $50 \mathrm{~ms}, 100 \mathrm{~ms}, 500 \mathrm{~ms}$, and $1000 \mathrm{~ms}$ for monkey $\mathrm{K}$, and amplitude between $50 \mu \mathrm{A}$ to $700 \mu \mathrm{A}$ for duration of $50 \mathrm{~ms}, 100 \mathrm{~ms}$, and 500 ms for monkey $\mathrm{O}$, while keeping pulse-width and frequency of stimulation constant (Figures 3c, $3 g$, and Supplementary Figure 2c). We observed that stimulation detection threshold significantly 
bioRxiv preprint doi: https://doi.org/10.1101/2020.05.09.085647; this version posted September 23, 2020. The copyright holder for this preprint (which was not certified by peer review) is the author/funder, who has granted bioRxiv a license to display the preprint in perpetuity. It is made available under aCC-BY-NC-ND 4.0 International license.

a

b

C

Monkey K
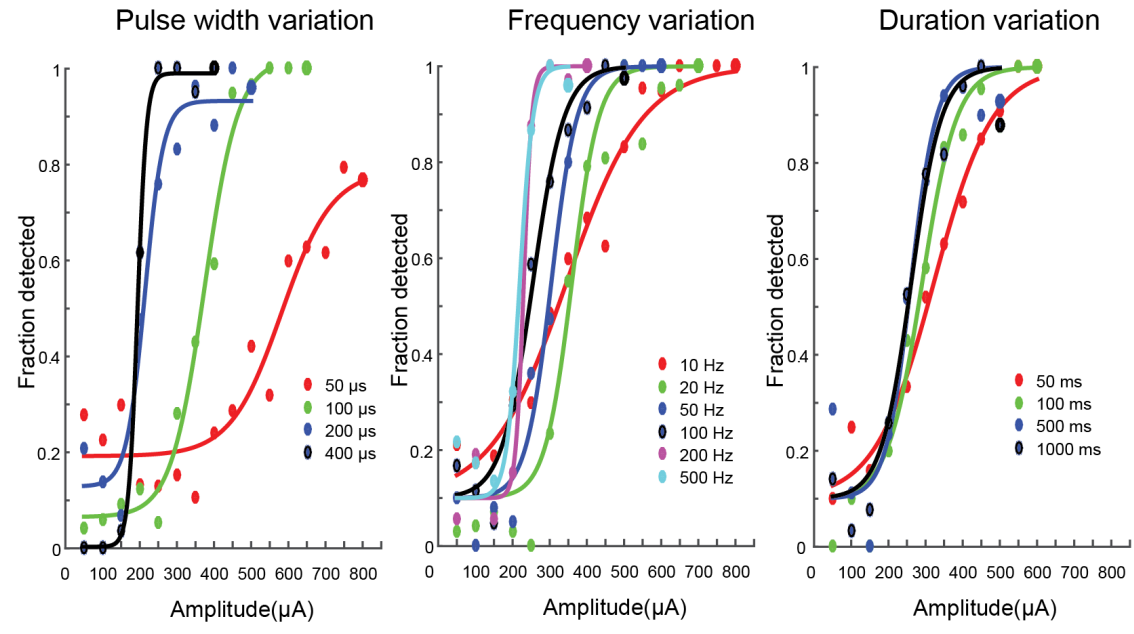

d

Duration and frequency variation

e

Pulse width variation

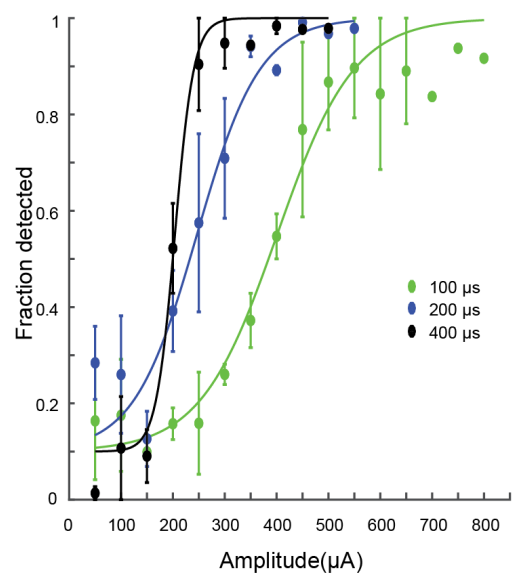

h

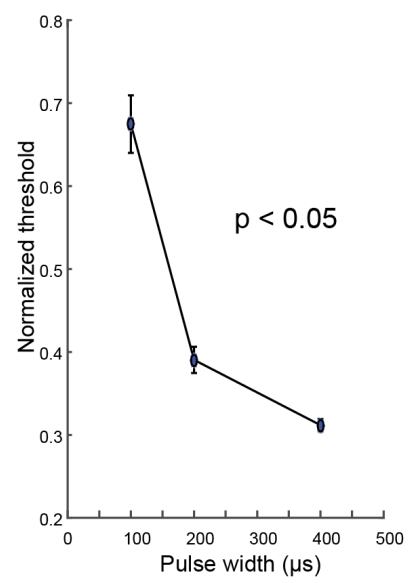

f

Monkeys $\mathrm{O}$ and $\mathrm{K}$

Frequency variation

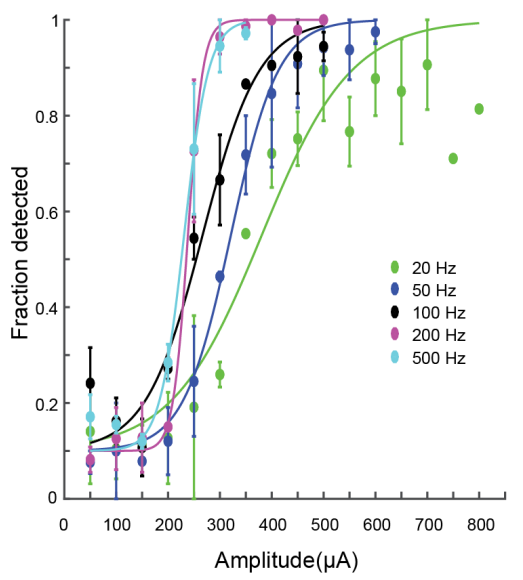

j

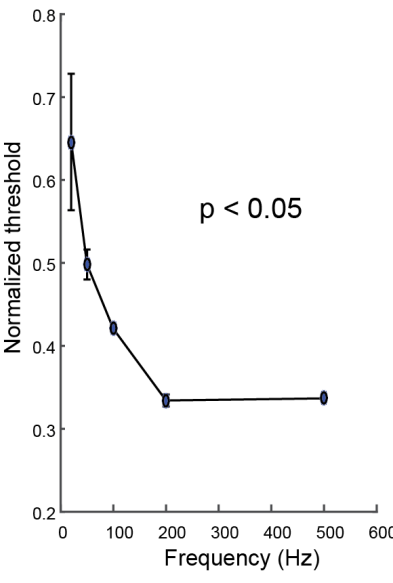

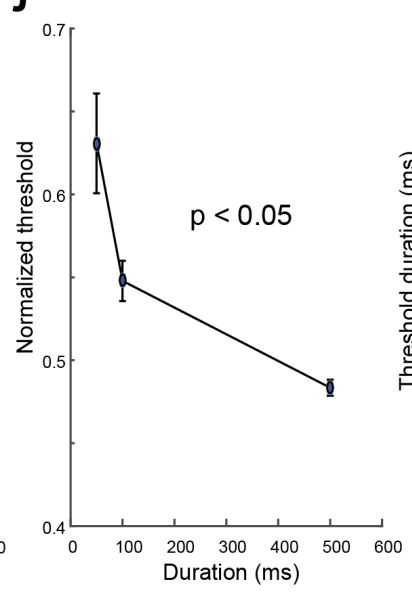

Duration variation

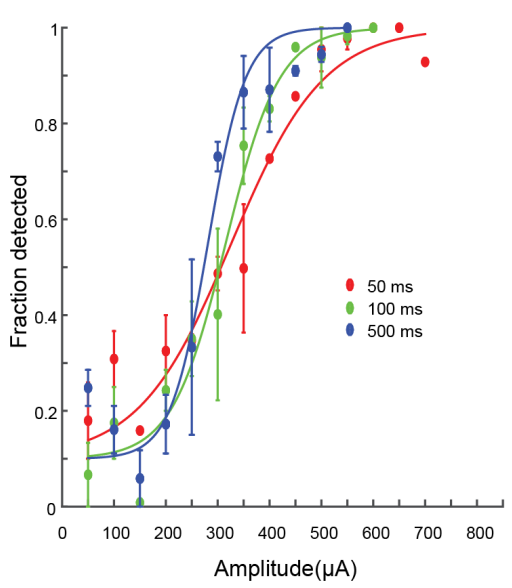

$\mathrm{k}$

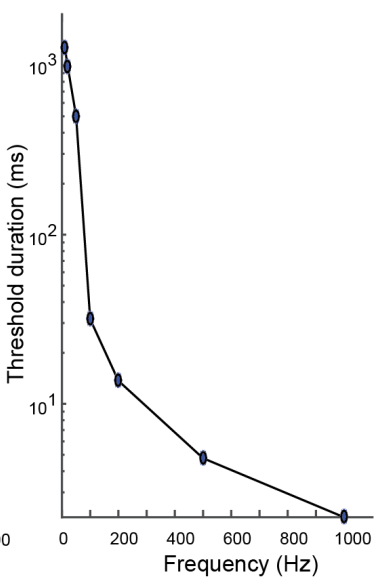


Figure 3: Psychophysical evaluation of SCS sensory detection with varying stimulation parameters in primates. Once monkeys learned to detect SCS stimuli at the standard parameters (frequency: $100 \mathrm{~Hz}$,

155 pulse width: $200 \mu$ s, duration: $1 \mathrm{sec}$ ), we allocated different blocks of sessions where (pulse width \& 156 amplitude; panels 'a' and 'e'); (frequency \& amplitude; panels 'b' and 'f'); and (duration \& amplitude; panels

157 ' $c$ ' and ' $g$ ') were varied while keeping other parameters constant. In monkey $\mathrm{K}$, in a separate block, frequency and duration was varied with other parameters constant (pulse width: $200 \mu$ sec and amplitude:

$159325 \mu \mathrm{A})$. Psychometric curves in a-g are sigmoidal fits. Panels a-d represent psychometric curves for

160 monkey $\mathrm{K}$, while panels e-g represent psychometric curves fitted to data averaged across monkeys $\mathrm{K}$ and

$161 \mathrm{O}$ (circles and error bars are mean \pm sem). Panels $\mathrm{h}, \mathrm{i}, \mathrm{j}$, indicate normalized detection thresholds

162 (normalized by maximum amplitude used in the experiment block of each individual monkey) averaged

163 across both monkeys (mean \pm sem). Detection threshold were calculated as $75 \%$ fraction detected at the 164 stimulation parameters shown in panels a-c (monkey K) and Supplementary Figure 2 a-c (monkey O). Pvalues were calculated using repeated measures one-way ANOVA. Panel k shows threshold duration obtained as $75 \%$ detection from curves in panel $d$ as a function of frequency. both animals (Figure $3 \mathrm{j})$.

In monkey $\mathrm{K}$, we varied both frequency and duration of stimulation while keeping amplitude and

171 pulse-width of stimulation constant. We observed that as the frequency of stimulation increased,

172 the duration of stimulation to reach detection threshold decreased (Figures 3d and 3k). Monkey

$173 \mathrm{~K}$ was able to detect a sensory percept generated by merely two stimulation pulses delivered at $1741000 \mathrm{~Hz}$.

176 We have previously shown that rats learn to detect sensations generated by epidural SCS 177 delivered at the T2 spinal level (14). In order to study the psychophysical performance of rats 

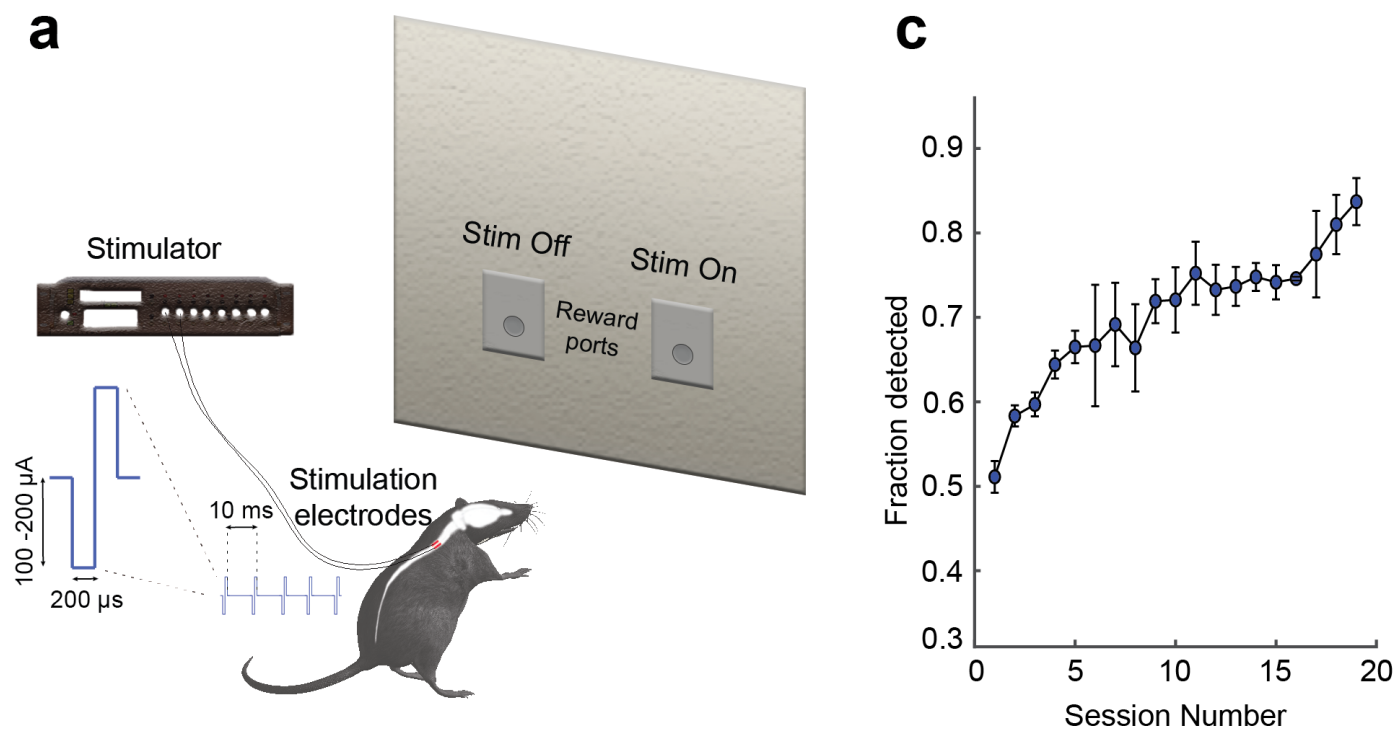

b

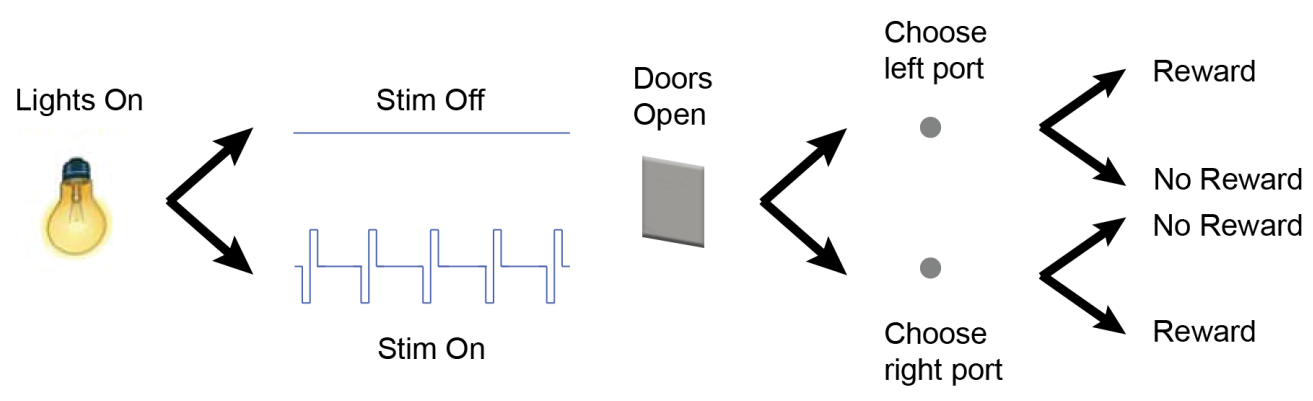

Figure 4: Behavioral task setup and rats learned to detect SCS stimuli. a) The experiment task consisted of a closed behavioral chamber with two reward ports on one side of the chamber. The ports were covered with vertical sliding doors. Five rats were implanted with bipolar stimulation electrodes on the dorsal surface of the spinal cord at the T3 spinal level. b) Task consisted of a house light turning 'on', followed by sensory cues for 1 second. During the cue period SCS was either delivered or not delivered. After the cue period both reward doors opened, and the rat had to make a nose poke response in either of the ports to receive water reward. If SCS was delivered rats had to poke inside the left port and if not delivered, then they had to poke inside the right reward port. Poking in the correct reward poke initiated a water reward, while incorrect pokes were not rewarded. c) Rats learned to detect SCS stimuli over a period of $15-25$ days as indicated - learning curve showing task performance indicated by fraction trials detected as a function of training sessions. Circles and error bars indicate mean \pm sem. 
a

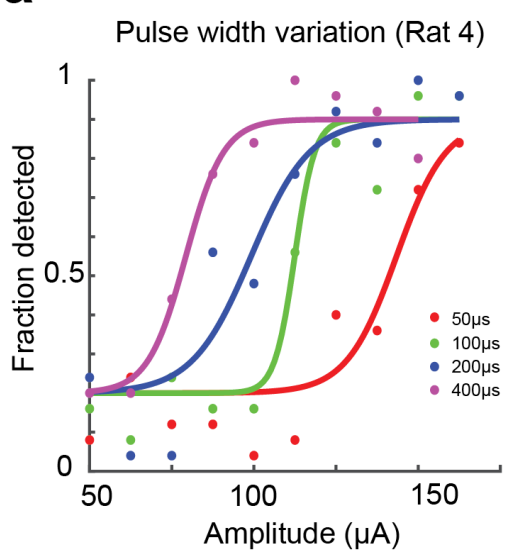

d

Pulse width variation (All rats)

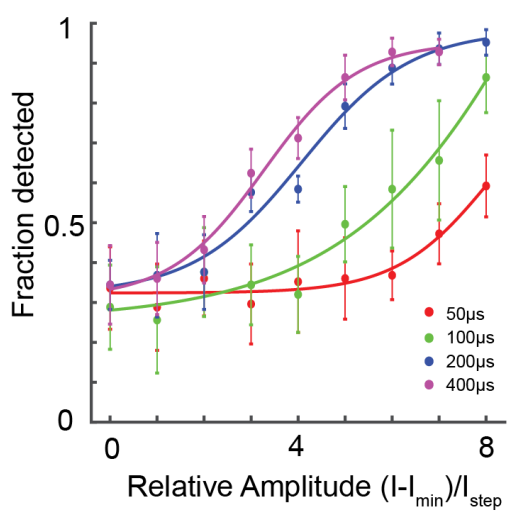

g

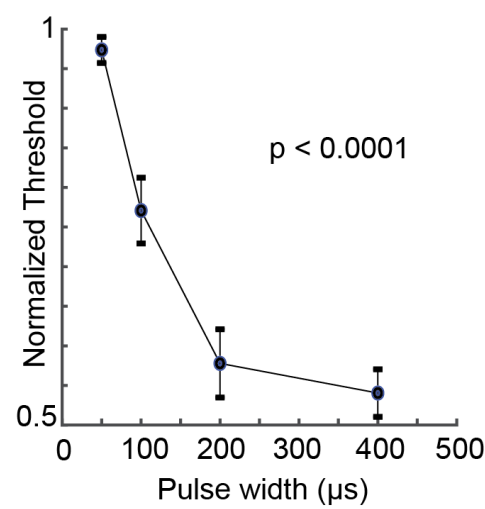

b

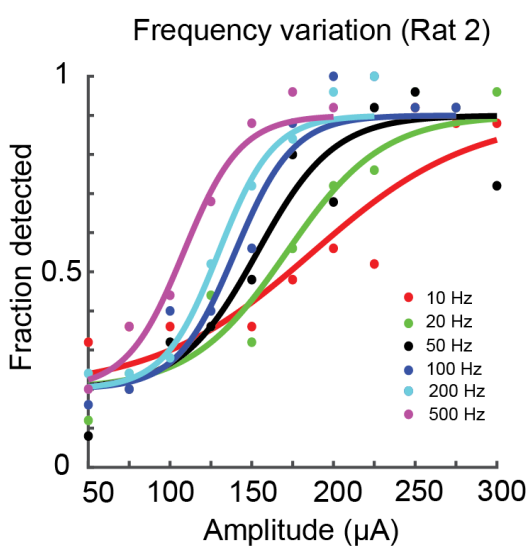

e Frequency variation (All rats)

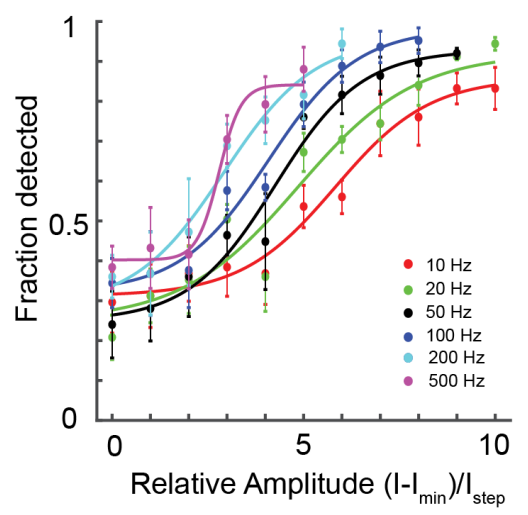

h

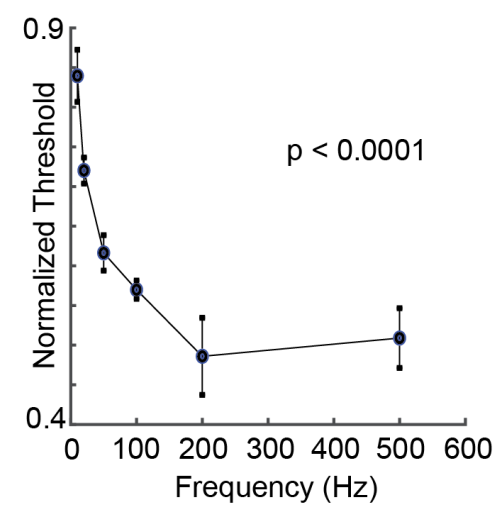

C

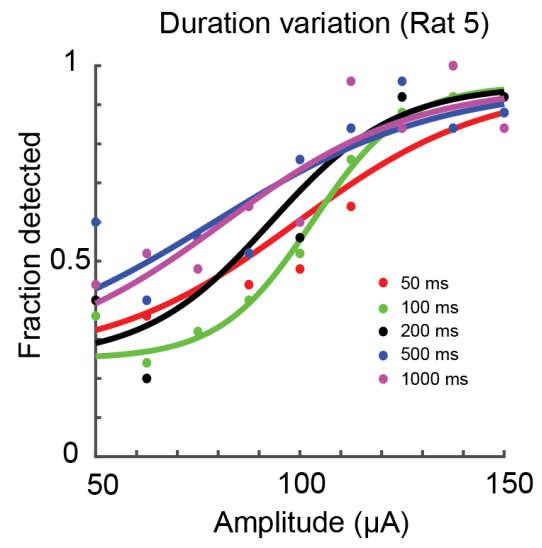

f

Duration variation (All rats)

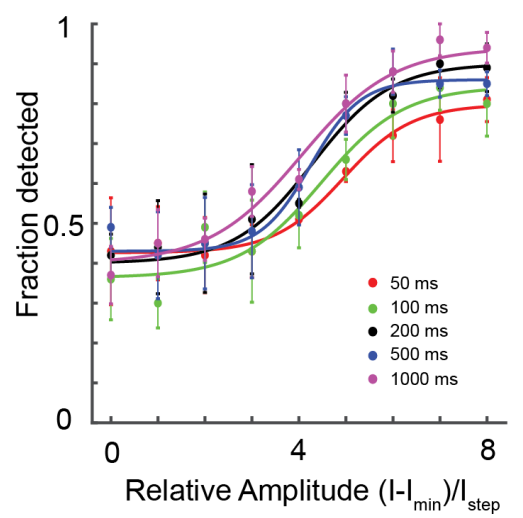

i

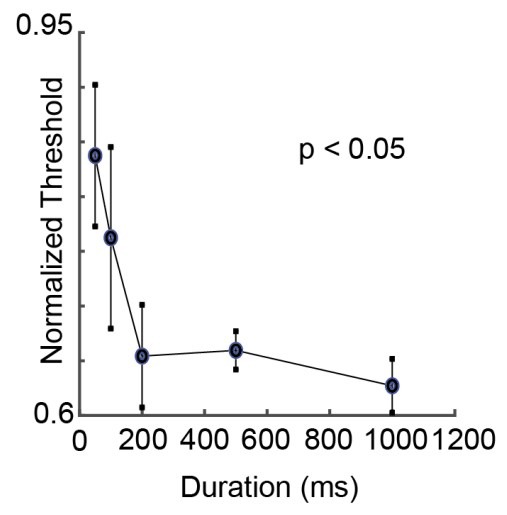

193 Figure 5: Psychophysical evaluation of SCS sensory detection with varying stimulation parameters in rats.

194 Once rats learned to detect SCS stimuli at the standard parameters (frequency: $100 \mathrm{~Hz}$, pulse width: 200 
195

196

197

198

199

200

201

202

203

204

205

206

207

208

209

210

211

212

213

214

215

216

217

218 $\mu$ s, duration: $1 \mathrm{sec}$ ), we allocated different blocks of sessions where (pulse width \& amplitude; panel 'a'); (frequency \& amplitude; panel 'b'); and (duration \& amplitude; panel 'c') were varied while keeping other parameters constant. a, b, c) Psychometric curves from representative rats showing a leftward shift of curves as the pulse-width (rat 4), frequency (rat 2), and duration (rat 5) of stimulation increased. d, e, f) Psychometric curves with averaged data across five rats indicate leftward shift as pulse-width, frequency, and duration are increased. X-axis represents relative amplitude values (for each rat raw amplitude values were subtracted by minimum amplitude and the difference was divided by amplitude step size). Circles and error bars are mean \pm sem across five rats. Curves in panels 'a-f' are sigmoidal fits. Panels 'g', 'h', and 'i' indicate normalized detection thresholds. Thresholds were calculated as $75 \%$ fraction detected at different stimulation parameters consistent with panels 'a-f' and then normalized by maximum amplitude used in the experimental block of each rat. Circles and error bars are mean \pm sem across five rats. P-values were calculated using repeated measures one-way ANOVA.

pertaining to sensory detection, initially we trained rats to detect SCS stimuli using a 2-AFC task in a slightly modified behavioral chamber (Figure $4 a$ and $4 b$ ). We trained five rats to detect SCS stimuli delivered at the T3 spinal level (frequency: $100 \mathrm{~Hz}$, pulse-width: $200 \mu \mathrm{s}$, duration: $1 \mathrm{sec}$, biphasic pulses at $243.7 \pm 57.9 \mu \mathrm{A}$, Figure $4 \mathrm{c}$ ).

Once rats learned the basic detection task, we varied stimulation parameters such as: pulse width $(50-400 \mu \mathrm{s})$; frequency $(10-500 \mathrm{~Hz})$; and duration $(50-1000 \mathrm{~ms})$ independently with stimulation amplitude (Figures 5a, 5d - pulse width; 5b, 5e - frequency; and 5c, $5 f$ - duration). Similar to the results in monkeys, we observed that stimulation detection thresholds significantly decreased with increasing pulse-width (Figure $5 \mathrm{~g}, \mathrm{p}<0.0001$, repeated measures one-way ANOVA), frequency (Figure $5 \mathrm{~h}, \mathrm{p}<0.0001$, repeated measures one-way ANOVA) and duration (Figure 5i, $p<0.05$, repeated measures one-way ANOVA) for all rats. 

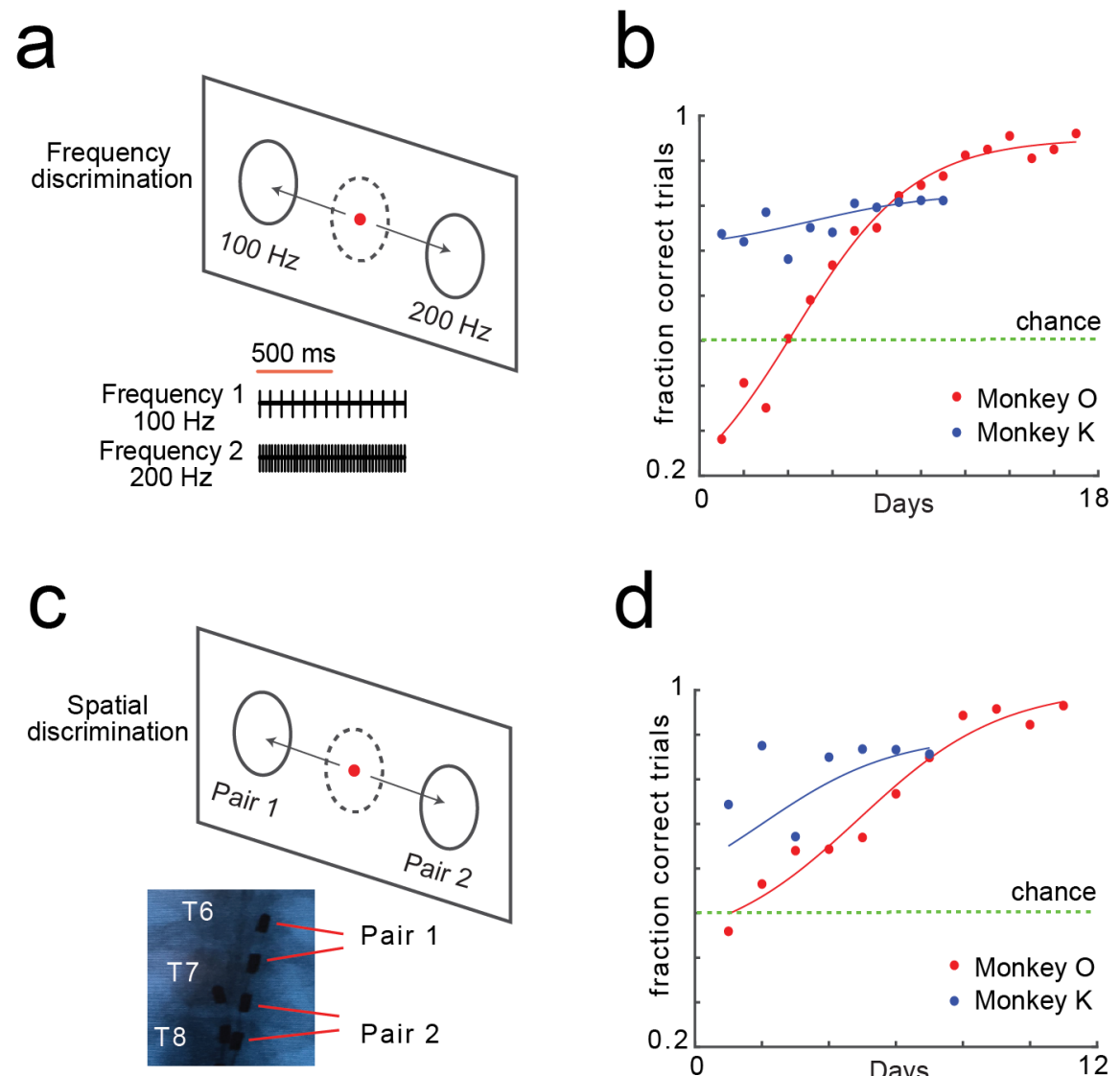

222 Figure 6: Monkeys learned to discriminate SCS stimuli varying in frequency and spatial location of

223 electrodes. a,b) Monkeys $\mathrm{K}$ and $\mathrm{O}$ learned to discriminate SCS stimuli delivered at the same electrode 224 location but varying in frequency $(100 \mathrm{~Hz}$ vs $200 \mathrm{~Hz})$. Monkey $\mathrm{O}$ was stimulated at same amplitude while 225 monkey $\mathrm{K}$ was stimulated at the respective threshold amplitude for $100 \mathrm{~Hz}$ and $200 \mathrm{~Hz}$. c,d) Monkeys $\mathrm{K}$ 226 and O learned to discriminate stimulation delivered at electrode pair 1 (T6 - T7 spinal level) vs electrode

227 pair 2 (T7-T8 spinal level). Curves in panels $b$ and d indicate sigmoidal fits to fraction correct trials displayed 228 as a function of training days. 
232 of stimulation. On frequency discrimination (100 Hz vs $200 \mathrm{~Hz}$, Figure 6a), monkey O's

233 performance improved from $29 \%$ on day 1 to $96 \%$ on day 17 of training, while monkey K's

234 performance improved from $74 \%$ on day 1 to $81 \%$ on day 11 (Figure $6 \mathrm{~b}$ ). Spatial discrimination

235 was achieved by stimulating electrode pair 1 versus electrode pair 2 (Figure 6c), where monkey

236 O's performance improved from $46 \%$ on day 1 to $97 \%$ on day 11 and monkey K's performance

237 improved from $74 \%$ on day 1 to $86 \%$ on day 7 (Figure $6 \mathrm{~d}$ ).

Sensory discrimination and Weber's law in rats

We had previously shown that rats can learn to discriminate up to four different time-varying patterns of stimulation (14). In our current work, we trained rats to discriminate SCS stimuli with different frequencies using the same behavioral setup that was used for the detection task

242 (Supplementary Figure 4a). In the basic training, rats learned to discriminate between $10 \mathrm{~Hz}$ and

$243100 \mathrm{~Hz}$ of stimulation delivered at pulse-width of $200 \mu \mathrm{sec}$, and duration of $1 \mathrm{sec}$ (Supplementary

244 Figure 4b). Thereafter, we studied whether discrimination of sensations induced by different stimulation frequencies follows the rules of Weber's law (16), which states that Just-Noticeable Differences (JNDs) between a standard frequency and comparison frequency should linearly increase with the standard frequency of stimulation. To this end, we determined JNDs at different standard frequencies $(10-100 \mathrm{~Hz})$ where the comparison frequency was higher than the standard (Figure 7a). We observed that JNDs had a significant linearly increasing relationship with the standard frequency of stimulation (Figure $7 b, p<0.0001$, linear regression test). After that, we kept the standard as a higher frequency value $(100-400 \mathrm{~Hz})$ and decreased the comparison frequency randomly from that value (Figure 7c). In this case also, we observed that the JNDs for lower frequency comparison significantly increased linearly as the standard 254 frequency increased (Figure $7 d, p<0.0001$, linear regression test). These results suggest that the 255 JND rule defined by Weber's law holds true for sensory discrimination of SCS frequencies. 

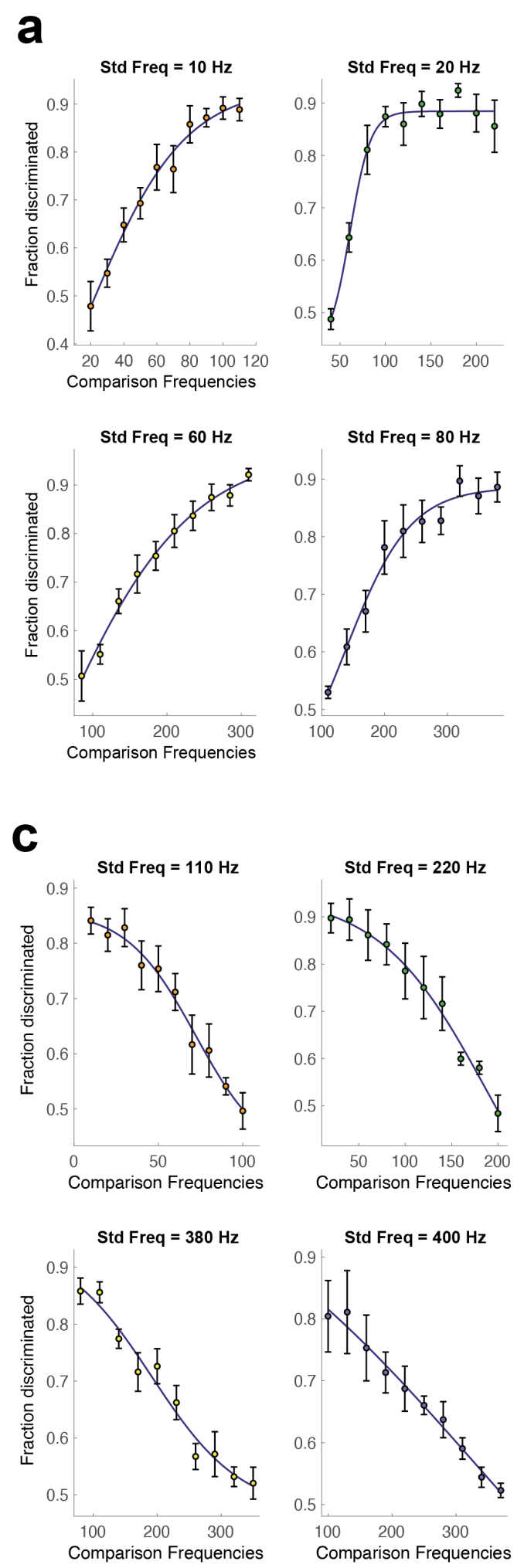

b
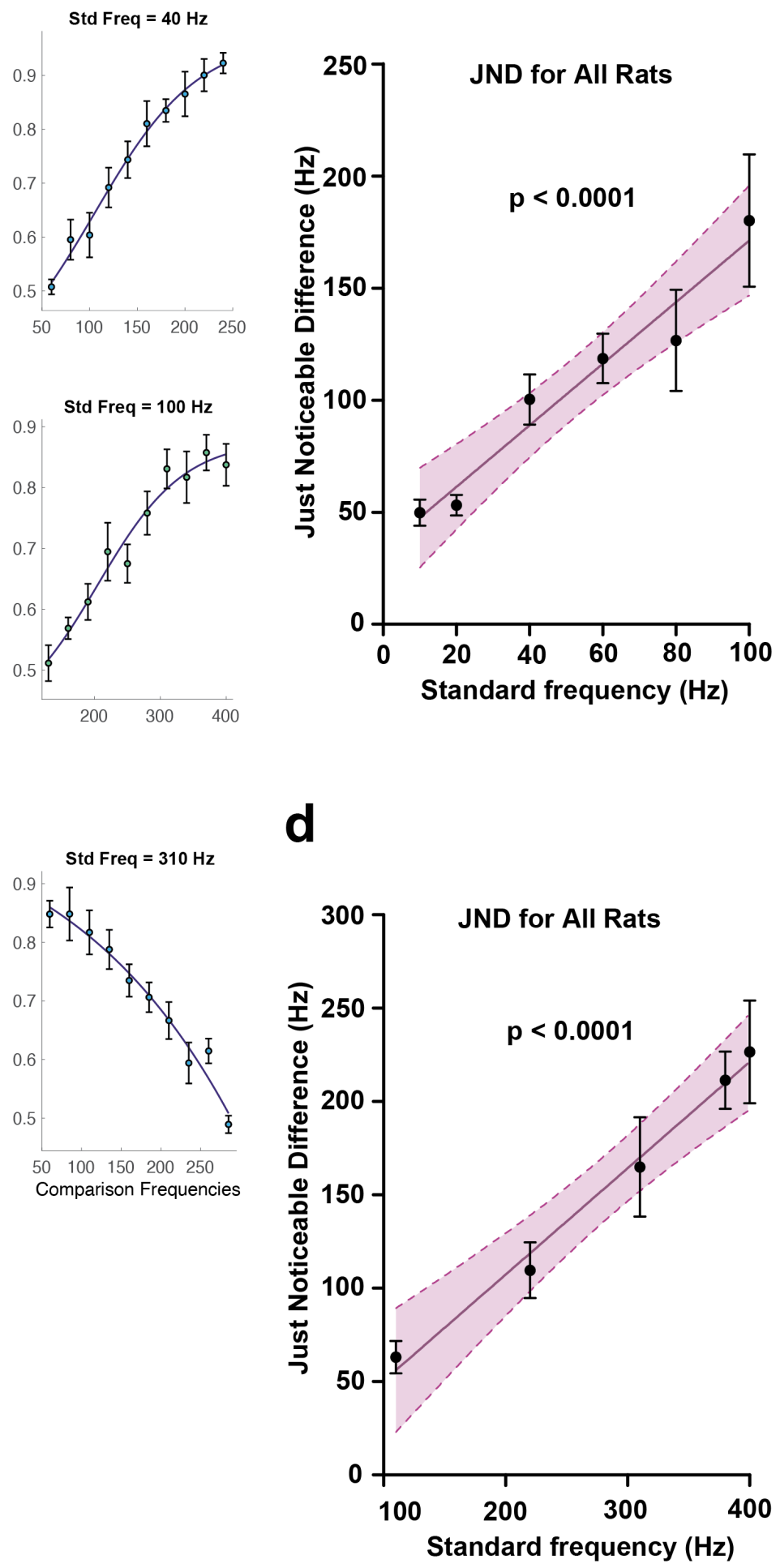
Figure 7: Discrimination of higher and lower comparison frequency obeys Weber's Law. a) Fraction of trials correctly discriminated from standard frequency of $10 \mathrm{~Hz}, 20 \mathrm{~Hz}, 40 \mathrm{~Hz}, 60 \mathrm{~Hz}, 80 \mathrm{~Hz}$, and $100 \mathrm{~Hz}$, when compared to a range of higher frequency stimuli. c) Fraction of trials correctly discriminated from standard frequency of $110 \mathrm{~Hz}, 220 \mathrm{~Hz}, 310 \mathrm{~Hz}, 380 \mathrm{~Hz}$, and $400 \mathrm{~Hz}$, when compared to a range of lower frequency stimuli. Circles and error bars in 'a' and 'c' indicate mean \pm sem. Curves indicate sigmoid fits to the data. Just noticeable difference (JND) is considered as the comparison frequency value that achieves $75 \%$ discrimination ability. b, d) Just noticeable difference as a function of standard frequency is indicated by black circles and error bars. Black line is linear regression fit to the data and pink bounds indicate $95 \%$ confidence bound of the regression line. JNDs associated with higher frequency and lower frequency comparison were significantly linearly related with standard frequency. P-values were calculated using linear regression test.

\section{Discussion}

272 In this study, we found that rhesus monkeys and rats can learn to detect and discriminate artificial

273 sensations induced by SCS following several days of exposure. The threshold for detecting SCS

274 decreases with increasing pulse width, frequency, and duration of the stimulus. We also

275 documented the ability of monkeys to discriminate sensations that are generated by stimulation

276 pulses with varying frequency and spatial location. In rats, we showed that the just-noticeable

277 differences (JNDs) from a perceivable stimulus frequency were linearly related to the perceivable

278 frequency when it was compared with a stimulus that had either higher or lower frequency. These

279 results demonstrated the unique ability of SCS as a novel transmission channel to the brain to encode highly contextual sensory information.

281 Our results on behavioral sensitivity to detection of sensation in rodents and primates were 282 comparable to those observed with Intracortical Microstimulation (ICMS) of S1 $(5,17)$. Notably, sensitivity to stimulus amplitude increased with increasing pulse width, frequency, and duration 
of stimulation. ICMS amplitude using currently FDA-approved UTAH arrays is usually restricted below $\sim 100 \mu \mathrm{A}$ due to the possibility of brain tissue damage, which limits the amplitude range for neuroprosthetic applications between detection thresholds of 20 - $50 \mu \mathrm{A}$ and maximum allowable safe amplitude of $\sim 100 \mu \mathrm{A}$. In our SCS study, detection thresholds had a wider range from $200-$ $800 \mu \mathrm{A}$ at different stimulation settings and all detection thresholds were consistently on the nondamaging side of the boundary between damaging and non-damaging stimulation delineated by Shannon equation $[\log (D)=k-\log (Q)$, with $k=1.85]$ on log charge density versus log charge per phase plot (Supplementary Figure 3a) (18). Assuming a commercially accepted maximum charge density of $30 \mu \mathrm{C} / \mathrm{cm}^{2}$ and minimum pulse-width of $50 \mu \mathrm{s}(19)$, it could be estimated that maximum SCS current of $\sim 80 \mathrm{~mA}$ in monkeys and $\sim 3 \mathrm{~mA}$ in rats could be delivered using electrode contacts (monkeys: $0.1319 \mathrm{~cm}^{2}$; rats: $0.005 \mathrm{~cm}^{2}$ ) reported in our study without causing tissue damage.

Frequency modulation has been historically considered a promising method for providing sensory feedback with several studies showing that animals are capable of discriminating ICMS frequencies and that frequency modulation obeys Weber's law. (4, 20-22), While ICMS amplitude modulation in monkeys failed to follow Weber's law (5), experiments in rats showed that modulation of perceived intensity by amplitude and pulse-width modulation followed Weber's law 301 (17). In our study, we investigated whether rats and monkeys could learn to discriminate SCS 302 frequencies. Although monkeys $\mathrm{O}$ and $\mathrm{K}$ learned to discriminate $100 \mathrm{~Hz}$ SCS from $200 \mathrm{~Hz}$, after 303 taking a closer look at their learning curves it was evident that they displayed different learning behaviors in the frequency discrimination task (Figures $6 \mathrm{~b}$ and $6 \mathrm{~d}$ ). Monkey $\mathrm{O}$ started at lower discrimination performance at earlier training sessions but reached higher level of performance toward the end of training, whereas monkey K's performance started higher than chance and improved marginally as the training progressed. These differences in learning behavior could be 
values $(100 \mathrm{~Hz}$ and $200 \mathrm{~Hz}$ ) while monkey $\mathrm{K}$ was stimulated at each frequency's threshold amplitude. It is quite possible that monkey $O$ was discriminating differences in perceived

311 magnitudes of the sensory percepts while monkey $\mathrm{K}$ was discriminating differences in the

312 qualitative nature of the percepts induced. Rats are capable of discriminating temporal patterns

313 of SCS when the number of pulses are kept constant but the frequency of stimulus is varied (14).

314 In addition to that, our current results indicate that JNDs associated with SCS frequency

315 discrimination in rats clearly follow Weber's law because JNDs linearly increased with standard

316 stimulation frequency (Figure $7 b$ and $7 d$ ). There were at least three discriminable percepts

317 between $10 \mathrm{~Hz}$ and $200 \mathrm{~Hz}$. It can be argued that applying frequency modulation simultaneously

318 with amplitude and pulse-width modulation would potentially increase the number of distinct

319 discriminable percepts that are possible within the amplitude range allowed on current SCS

320 electrodes. Therefore, further experiments exploring the relationship between sensory

321 discrimination and frequency, pulse-width, amplitude, and duration of stimulation are necessary

322 to understand how these parameters relate to perceived intensity and quality of sensation evoked

323 by SCS.

324 A major advantage of SCS is its ability to target multiple dermatomes simultaneously with a single

325 electrode array. In particular, a single, commercially available SCS lead with multiple contacts

326 can evoke sensations in multiple dermatomes simultaneously due to the bilateral sensory

327 representation of the entire lower body in the ascending dorsal column fibers. It is quite apparent

328 from our results that monkeys can learn to discriminate the spatial location of the sensations

329 evoked by SCS (Figure 6d). This suggests that we can take full advantage of the medio-

330 lateral/rostro-caudal somatotopy represented in the dorsal column fibers in combination with

331 spatiotemporal stimulation patterns to electrically induce targeted tactile or proprioceptive

332 sensations in the body. This view is also supported by evidence from computational studies which

333 indicate that epidural SCS activates dorsal column fibers up to a depth of 0.2-0.25 mm from the 
dorsal surface (23-27). However, additional work on miniaturizing electrode contacts and accurate mapping of SCS-induced sensations needs to be performed to be able to elicit precise sensations. In addition, the ability of SCS to modulate neuronal activity in supraspinal brain structures is quite

337 desirable from a neuroprosthetic as well as a therapeutic application standpoint (14, 28-31). A

338 major limitation of our study is the short experimental time (Supplementary Figure 1a) we had 339 available for primates - maximum of 5 months - due to the risk of infection associated with externalized SCS leads. A fully implantable stimulation system, like the one implanted in chronic pain patients could potentially extend our study indefinitely and allow us to perform longer experiments in monkeys. Nevertheless, in rodents we were able to perform longer post-implant experiments because the electrodes and their wires were fully enclosed inside the body.

In conclusion, we have successfully demonstrated that SCS can be used to encode sensory information in both rats and monkeys and all together our results demonstrate that SCS-induced sensations obey a robust encoding scheme in the brain. Additionally, our behavioral experiments serve as a test bed for future animal studies which could elucidate the neural mechanisms underlying SCS-based sensory detection and discrimination. We envision that SCS can be developed as an artificial sensory feedback channel for delivering targeted tactile and proprioceptive information to the brain.

\section{Methods}

353 All animal procedures were approved by the Duke University Institutional Animal Care and Use 354 Committee and in accordance with National Institute of Health Guide for the Care and Use of 355 Laboratory Animals. Three adult rhesus macaque monkeys (Macaca mulatta), monkeys 'M', 'O', 356 and ' $\mathrm{K}$ ' and Long Evans rats (300 - $350 \mathrm{~g})$ participated in the experiments. 
Monkeys M, K, and O were implanted with 8-contact cylindrical percutaneous leads (Model 3186, diameter $1.4 \mathrm{~mm}$, contact length $3 \mathrm{~mm}$, spacing $4 \mathrm{~mm}$, Abbott Laboratories) bilaterally to the spinal mid-line in the dorsal epidural space at T6 - T8 spinal level. Monkey M had two leads with 8 stimulation contacts each, monkey $\mathrm{O}$ had two leads, one with 8 contacts (right side) and one with 4 contacts (left side, Model 3146, similar electrode contact dimensions as Model 3186), and monkey $\mathrm{K}$ had two leads with 8 stimulation contacts each. Experimental procedures for monkeys $\mathrm{M}, \mathrm{O}$, and $\mathrm{K}$ lasted approximately 45,135 , and 150 days post-implant after which the leads were explanted (Supplementary Figure 1a).

Implant surgery was performed under general anesthesia using standard procedures typical of

367 human implantation (for details see supplementary information and Supplementary Figures $1 \mathrm{~b}$ and 1c). Once leads were implanted in the epidural space, a small hole was created in the skin off-midline to externalize the distal end of the lead. Externalized leads were enclosed in a custom plastic cap which was sutured to the skin (Supplementary Figure 1d). The plastic cap allowed for access to the leads by the researcher but protection from the animal. The animal wore a protective

372 vest after surgery and throughout the experimental period which prevented its access to the 373 plastic cap sutures to its back.

\section{Monkey SCS detection task}

Monkeys were trained to perform a two-alternative forced choice task where they were seated in center target appeared, and the monkey had to move a cursor which was joystick-controlled inside the center target (Figure 1c). After a brief hold period of 500 milliseconds (ms) inside the center

379 target, two targets appeared on either side of the center target. Each monkey had to hold the 380 cursor inside the central target for a brief period of $500 \mathrm{~ms}-1$ second. During this hold period 381 movement cues were presented. If SCS was presented (charge-balanced, cathode-first, $200 \mu \mathrm{s}$ 382 biphasic square pulses at $100 \mathrm{~Hz}$ for 1 second using custom microstimulator (32)), then the 
monkey had to move the cursor to the left target to obtain a juice reward. If SCS was absent, then the monkey had to move the cursor inside the right target. At the end of the hold period, the center target disappeared, thus cuing the monkey to initiate cursor movement toward the reward. Incorrect target reaches were not rewarded. Initiation of movement prior to the end of the hold

387 period terminated the trial without reward and a blank screen was displayed 3 seconds before 388 starting next trial. The learning performance of monkeys was studied using percentage correct 389 (PC) trials.

Once monkeys were trained on the detection task, detection thresholds were determined for different electrode combinations using psychometric testing. Particularly, during 'Stimulation ON' i.e. 'left target rewarded' trials, the stimulation amplitude was randomly varied from $50 \mu \mathrm{A}$ to a manually determined upper limit which was below the motor threshold. Only left target trials were analyzed and a percentage correct (PC) performance at each stimulation amplitude value was determined. A sigmoid curve was fit to the PC values and $75 \%$ was considered as detection threshold. This was repeated for several electrode combinations.

\section{Monkey electrode mapping}

399 In monkey K, once sensory detection thresholds were determined, we mapped the location of 400 electrode pairs to location on the monkey's body by sedating the monkey and stimulating those 401 electrodes above the sensory threshold values. Areas on the body surface that elicited minor 402 muscle twitches or skin flutter were marked (Figure 2c, left) and the motor thresholds were noted. 403 In monkey $\mathrm{O}$, these observations were not made under sedation but while it was seated in the 404 primate chair. 
During sets of consecutive sessions, we varied amplitude and frequency or amplitude and pulse-

407 width or amplitude and duration of stimulation while keeping other parameters constant (for

408 stimulation parameter ranges, see Supplementary Table 1). The standard parameters that

409 remained constant while others were varied were frequency: $100 \mathrm{~Hz}$, pulse width: $200 \mu \mathrm{sec}$, and

410 duration: $1 \mathrm{sec}$. In monkey $\mathrm{K}$, we varied frequency $(10-1000 \mathrm{~Hz})$ and duration $(1-2000 \mathrm{~ms})$ of

411 stimulation simultaneously while keeping pulse width and amplitude constant at $200 \mu$ and 325

$412 \mu \mathrm{A}$ respectively. Detection thresholds for each monkey were normalized by maximum amplitude

413 used in the experiment block of that monkey before statistical analysis.

Monkey sensory discrimination

415 In the frequency discrimination task, each monkey was instructed to move the cursor inside the 416 left target for $100 \mathrm{~Hz}$ and right target for $200 \mathrm{~Hz}$ respectively (Figure 6a). In the spatial 417 discrimination task, the monkey was instructed to move the cursor inside the left target for 418 electrode pair 1 and inside right target for electrode pair 2 respectively (Figure 6c).

419 Rat pre-training and SCS electrode implantation

420 Moderately water deprived rats were placed inside the behavioral chamber for 2 days to 421 acclimatize to the behavioral environment. The behavioral chamber had two doors on one side of

422 the walls which enclosed water reward ports (Figure 4a), slightly modified from the one previously 423 described (33). Rats were gradually trained to receive water reward from the ports. Initially, both 424 reward doors were kept open and rats learned to receive water by licking at the water dispensing 425 spout. Later, the doors were kept closed and would open a few seconds after the house light 426 turned on. In subsequent sessions, left and right doors would open on alternate trials and rats 427 learned to obtain reward from each port alternatively. The pre-surgical training period lasted 428 approximately $8-10$ days. 
429 Thereafter custom designed SCS electrodes ( $1 \mathrm{~mm} \times 0.5 \mathrm{~mm}$ contacts arranged transversely in

430 a bipolar configuration with $0.25 \mathrm{~mm}$ spacing using a $0.025 \mathrm{~mm}$ thickness platinum foil, Goodfellow

431 Cambridge Limited, England) were implanted into the epidural space under T3 vertebra as

432 described in our previous article (29). After the rats recovered from the spinal surgical procedures,

433 cathode leading stimulation pulse trains were delivered at the SCS electrodes using a multi-

434 channel constant current stimulator (Master-8, A.M.P.I, Jerusalem, Israel) at stimulation settings

435 which were determined depending on the behavioral task under consideration (Figure 4a).

Rat sensory detection task

After recovery from surgery, rats were introduced to a two-alternative forced choice task (2AFC) of cathode-leading bipolar square pulse trains (pulse width: $200 \mu \mathrm{s}$, Frequency: $100 \mathrm{~Hz}$, duration:

reward doors opened, and rats had to respond by choosing the left door for 'SCS ON' trials and right door for 'SCS OFF' trials. Incorrect responses were not rewarded. During the learning of this basic detection task, the intensity of the delivered current was determined before each session and set using procedures described before $(14,29,31)$ (mean \pm std, intensity at $100 \mathrm{~Hz}$ was 243.7

$447 \pm 57.9 \mu \mathrm{A})$.

\section{Rat sensory detection psychophysics}

449 Once rats learned the basic sensory detection task and their performance was above $80 \%$, 450 stimulation parameters were varied in a systematic manner during the SCS-ON trials. In different experimental sessions, stimulation parameters such as frequency and amplitude, pulse-width and 
453 constant (standard parameters: pulse width: $200 \mu \mathrm{s}$; Frequency: $100 \mathrm{~Hz}$; duration: 1 s), and

454 sensory detection threshold amplitude was determined (for stimulation parameter ranges see

455 Supplementary Table 1). For all the conditions, the detectable level of the amplitude was defined

456 as $75 \%$ accuracy of behavioral performance. Detection thresholds for each rat were normalized

457 by maximum amplitude used in the experiment block of that rat before statistical analysis.

Rat sensory discrimination task

In a $2 A F C$ task, rats were presented with either a low frequency stimulus or a high frequency

460 stimulus during the sensory cue period in the behavioral chamber. For either frequency, the

461 stimulus was delivered at the same amplitude (determined at each session), pulse width (200 $\mu$ s),

462 and duration $(1 \mathrm{sec})$. After a brief delay period following sensory cue presentation, rats had to

463 choose the left door for higher frequency stimulus and right door for lower frequency stimulus to

464 obtain reward (Supplementary Figure 4a). Initially, rats were trained to discriminate between 10

$465 \mathrm{~Hz}$ and $100 \mathrm{~Hz}$ frequency. Incorrect trails were not rewarded.

Weber's law and sensory discrimination

467 Once rats learned to discriminate $10 \mathrm{~Hz}$ stimulus from $100 \mathrm{~Hz}$ stimulus, demonstrated by 468 consistent discrimination performance above $80 \%$, the lower frequency (standard frequency) was 469 kept constant during right door trials while the higher frequency (comparison frequency) was 470 randomized between $20 \mathrm{~Hz}$ and $110 \mathrm{~Hz}$ during left door trials. Sensory discrimination performance

471 between a standard frequency and comparison frequency was determined as the fraction of trials 472 successfully discriminated for that particular standard and comparison pair. Thus, fraction trials 473 discriminated was plotted as a function of comparison frequency to obtain Just-Noticeable 474 Differences (JNDs) determined as $75 \%$ value on the curve. The same experiment was repeated 475 for different standard frequency values such as $20 \mathrm{~Hz}$ vs $(40-220 \mathrm{~Hz}), 40 \mathrm{~Hz}$ vs $(60-240 \mathrm{~Hz})$, 
477 for each standard frequency value and to test for Weber's law.

478 Similarly, the experiment was repeated for discrimination of a low-frequency comparison stimulus

479 from a high-frequency standard stimulus. The standard frequency values were 110, 220, 310,

480380 , and $400 \mathrm{~Hz}$, while the comparison frequency was randomized from $(100-10 \mathrm{~Hz}),(200-20$

$481 \mathrm{~Hz}),(285-60 \mathrm{~Hz}),(350-80 \mathrm{~Hz})$, and $(370-100 \mathrm{~Hz})$ respectively for each of the standard

482 frequency values. JNDs were calculated for each of the standard frequency values as explained

483 before to test for Weber's law.

484 Statistical Analysis

485 Repeated measures one-way ANOVA was used to test the significance of relationship between

486 stimulation parameters and sensory detection thresholds in both rats and monkeys (Figures 3h,

$4873 \mathrm{i}, 3 \mathrm{j}, 5 \mathrm{~g}, 5 \mathrm{~h}$, and $5 \mathrm{i})$. To test whether JNDs were significantly linearly related to standard

488 frequency in the sensory discrimination task, the linear regression test was used (Figures $7 \mathrm{~b}$ and $4897 \mathrm{~d})$.

490

491

492

493

494

495

496

497

498

499

500

501 
502

503

504

505

506

507

508

509

510

511

512 24739786.

513

514

515

516

517

518

519

520

521

522 28275048.

\section{References}

1. Lebedev MA, Nicolelis MA. Brain-Machine Interfaces: From Basic Science to Neuroprostheses and Neurorehabilitation. Physiol Rev. 2017;97(2):767-837. doi: 10.1152/physrev.00027.2016. PubMed PMID:

2. Krucoff MO, Rahimpour S, Slutzky MW, Edgerton VR, Turner DA. Enhancing Nervous System Recovery through Neurobiologics, Neural Interface Training, and Neurorehabilitation. Frontiers in neuroscience. 2016;10. doi: ARTN 584

10.3389/fnins.2016.00584. PubMed PMID: WOS:000390598100001.

3. Bensmaia SJ, Miller LE. Restoring sensorimotor function through intracortical interfaces: progress and looming challenges. Nat Rev Neurosci. 2014;15(5):313-25. doi: 10.1038/nrn3724. PubMed PMID:

4. O'Doherty JE, Lebedev MA, Ifft PJ, Zhuang KZ, Shokur S, Bleuler H, Nicolelis MA. Active tactile exploration using a brain-machine-brain interface. Nature. 2011;479(7372):228-31. doi: 10.1038/nature10489. PubMed PMID: 21976021; PMCID: 3236080.

5. Kim S, Callier T, Tabot GA, Gaunt RA, Tenore FV, Bensmaia SJ. Behavioral assessment of sensitivity to intracortical microstimulation of primate somatosensory cortex. Proceedings of the National Academy of Sciences of the United States of America. 2015;112(49):15202-7. doi: 10.1073/pnas.1509265112. PubMed PMID: 26504211; PMCID: 4679002.

6. Tabot GA, Dammann JF, Berg JA, Tenore FV, Boback JL, Vogelstein RJ, Bensmaia SJ. Restoring the sense of touch with a prosthetic hand through a brain interface. P Natl Acad Sci USA. 2013;110(45):18279-

84. doi: 10.1073/pnas.1221113110. PubMed PMID: WOS:000326550800062. 
523 7. Flesher SN, Collinger JL, Foldes ST, Weiss JM, Downey JE, Tyler-Kabara EC, Bensmaia SJ, Schwartz

$524 A B$, Boninger ML, Gaunt RA. Intracortical microstimulation of human somatosensory cortex. Science

525 translational medicine. 2016;8(361):361ra141. Epub 2016/11/01. doi: 10.1126/scitranslmed.aaf8083.

526 PubMed PMID: 27738096.

527 8. Heming E, Sanden A, Kiss ZH. Designing a somatosensory neural prosthesis: percepts evoked by 528 different patterns of thalamic stimulation. Journal of neural engineering. 2010;7(6):064001. doi: 529 10.1088/1741-2560/7/6/064001. PubMed PMID: 21084731.

530 9. Swan BD, Gasperson LB, Krucoff MO, Grill WM, Turner DA. Sensory percepts induced by microwire 531 array and DBS microstimulation in human sensory thalamus. Brain Stimul. 2018;11(2):416-22. doi: 532 10.1016/j.brs.2017.10.017. PubMed PMID: 29126946; PMCID: PMC5803348.

533 10. Dadarlat MC, O'Doherty JE, Sabes PN. A learning-based approach to artificial sensory feedback 534 leads to optimal integration. Nature neuroscience. 2015;18(1):138-44. Epub 2014/11/25. doi: 535 10.1038/nn.3883. PubMed PMID: 25420067; PMCID: PMC4282864.

536 11. Strauss I, Valle G, Artoni F, D'Anna E, Granata G, Di lorio R, Guiraud D, Stieglitz T, Rossini PM, 537 Raspopovic S, Petrini FM, Micera S. Characterization of multi-channel intraneural stimulation in 538 transradial amputees. Sci Rep. 2019;9(1):19258. Epub 2019/12/19. doi: 10.1038/s41598-019-55591-z. 539 PubMed PMID: 31848384; PMCID: PMC6917705.

540 12. Petrini FM, Valle G, Bumbasirevic M, Barberi F, Bortolotti D, Cvancara P, Hiairrassary A, Mijovic P, 541 Sverrisson AO, Pedrocchi A, Divoux JL, Popovic I, Lechler K, Mijovic B, Guiraud D, Stieglitz T, Alexandersson 542 A, Micera S, Lesic A, Raspopovic S. Enhancing functional abilities and cognitive integration of the lower 543 limb prosthesis. Science translational medicine. 2019;11(512). Epub 2019/10/04. doi: 544 10.1126/scitranslmed.aav8939. PubMed PMID: 31578244. 
545 13. Petrini FM, Bumbasirevic M, Valle G, llic V, Mijovic P, Cvancara P, Barberi F, Katic N, Bortolotti D,

546 Andreu D, Lechler K, Lesic A, Mazic S, Mijovic B, Guiraud D, Stieglitz T, Alexandersson A, Micera S,

547 Raspopovic S. Sensory feedback restoration in leg amputees improves walking speed, metabolic cost and

548 phantom pain. Nat Med. 2019;25(9):1356-63. Epub 2019/09/11. doi: 10.1038/s41591-019-0567-3.

549 PubMed PMID: 31501600.

550 14. Yadav AP, Li D, Nicolelis MAL. A Brain to Spine Interface for Transferring Artificial Sensory

551 Information. Sci Rep. 2020;10(1):900. Epub 2020/01/23. doi: 10.1038/s41598-020-57617-3. PubMed

552 PMID: 31964948.

553 15. Bellanca RU, Lee GH, Vogel K, Ahrens J, Kroeker R, Thom JP, Worlein JM. A simple alopecia scoring 554 system for use in colony management of laboratory-housed primates. J Med Primatol. 2014;43(3):153-61.

555 Epub 2014/02/28. doi: 10.1111/jmp.12107. PubMed PMID: 24571509; PMCID: PMC4438708.

556 16. Ekman G. Weber Law and Related Functions. Journal of Psychology. 1959;47(2):343-52. doi: Doi 557 10.1080/00223980.1959.9916336. PubMed PMID: WOS:A1959CAK1200020.

558 17. Bjanes DA, Moritz CT. A Robust Encoding Scheme for Delivering Artificial Sensory Information via 559 Direct Brain Stimulation. IEEE Trans Neural Syst Rehabil Eng. 2019;27(10):1994-2004. Epub 2019/08/24. 560 doi: 10.1109/TNSRE.2019.2936739. PubMed PMID: 31443035.

561 18. Merrill DR, Bikson M, Jefferys JG. Electrical stimulation of excitable tissue: design of efficacious 562 and safe protocols. J Neurosci Methods. 2005;141(2):171-98. Epub 2005/01/22. doi: 
564 19. Cogan SF, Ludwig KA, Welle CG, Takmakov P. Tissue damage thresholds during therapeutic

565 electrical stimulation. Journal of neural engineering. 2016;13(2):021001. Epub 2016/01/23. doi:

566 10.1088/1741-2560/13/2/021001. PubMed PMID: 26792176; PMCID: PMC5386002.

567 20. Romo R, Hernandez A, Zainos A, Brody CD, Lemus L. Sensing without touching: psychophysical

568 performance based on cortical microstimulation. Neuron. 2000;26(1):273-8. PubMed PMID: 10798410.

569 21. O'Doherty JE, Shokur S, Medina LE, Lebedev MA, Nicolelis MAL. Creating a neuroprosthesis for 570 active tactile exploration of textures. Proceedings of the National Academy of Sciences of the United

571 States of America. 2019;116(43):21821-7. Epub 2019/10/09. doi: 10.1073/pnas.1908008116. PubMed

572 PMID: 31591224; PMCID: PMC6815176.

573 22. Callier T, Brantly NW, Caravelli A, Bensmaia SJ. The frequency of cortical microstimulation shapes

574 artificial touch. Proceedings of the National Academy of Sciences of the United States of America.

575 2020;117(2):1191-200. Epub 2019/12/28. doi: 10.1073/pnas.1916453117. PubMed PMID: 31879342;

576 PMCID: PMC6969512.

$57723 . \quad$ Holsheimer J, Barolat G. Spinal geometry and paresthesia coverage in spinal cord stimulation.

578 Neuromodulation : journal of the International Neuromodulation Society. 1998;1(3):129-36. doi:

579 10.1111/j.1525-1403.1998.tb00006.x. PubMed PMID: 22150980.

580 24. Barolat G, Massaro F, He J, Zeme S, Ketcik B. Mapping of sensory responses to epidural stimulation

581 of the intraspinal neural structures in man. Journal of neurosurgery. 1993;78(2):233-9. Epub 1993/02/01.

582 doi: 10.3171/jns.1993.78.2.0233. PubMed PMID: 8421206. 
583 25. Holsheimer J, Buitenweg JR. Review: Bioelectrical mechanisms in spinal cord stimulation.

584 Neuromodulation : journal of the International Neuromodulation Society. 2015;18(3):161-70; discussion

585 70. doi: 10.1111/ner.12279. PubMed PMID: 25832787.

586 26. North RB, Sieracki JM, Fowler KR, Alvarez B, Cutchis PN. Patient-interactive, microprocessor-

587 controlled neurological stimulation system. Neuromodulation : journal of the International

588 Neuromodulation Society. 1998;1(4):185-93. Epub 1998/10/01. doi: 10.1111/j.1525-

589 1403.1998.tb00015.x. PubMed PMID: 22151030.

590 27. Holsheimer J. Which Neuronal Elements are Activated Directly by Spinal Cord Stimulation.

591 Neuromodulation : journal of the International Neuromodulation Society. 2002;5(1):25-31. Epub

592 2002/01/01. doi: 10.1046/j.1525-1403.2002._2005.x. PubMed PMID: 22151778.

593 28. Yadav AP, Nicolelis MAL. Electrical stimulation of the dorsal columns of the spinal cord for

594 Parkinson's disease. Mov Disord. 2017;32(6):820-32. doi: 10.1002/mds.27033. PubMed PMID: 28497877.

595 29. Yadav AP, Fuentes R, Zhang H, Vinholo T, Wang CH, Freire MA, Nicolelis MA. Chronic spinal cord 596 electrical stimulation protects against 6-hydroxydopamine lesions. Sci Rep. 2014;4:3839. doi: 597 10.1038/srep03839. PubMed PMID: 24452435; PMCID: 3899601.

598 30. Yadav AP, Borda E, Nicolelis MA. Closed loop spinal cord stimulation restores locomotion and 599 desynchronizes corticostriatal beta oscillations [abstract]. Mov Disord. 2018;33.

600 31. Pais-Vieira M, Yadav AP, Moreira D, Guggenmos D, Santos A, Lebedev M, Nicolelis MA. A Closed 601 Loop Brain-machine Interface for Epilepsy Control Using Dorsal Column Electrical Stimulation. Sci Rep. 602 2016;6:32814. doi: 10.1038/srep32814. PubMed PMID: 27605389; PMCID: PMC5015048. 
603 32. Hanson TL, Omarsson B, O'Doherty JE, Peikon ID, Lebedev MA, Nicolelis MA. High-side digitally

604 current controlled biphasic bipolar microstimulator. IEEE Trans Neural Syst Rehabil Eng. 2012;20(3):331-

605

40. Epub 2012/02/14. doi: 10.1109/TNSRE.2012.2187219. PubMed PMID: 22328184; PMCID:

606

PMC3502026.

607 33. Pais-Vieira M, Chiuffa G, Lebedev M, Yadav A, Nicolelis MA. Building an organic computing device

608 with multiple interconnected brains. Sci Rep. 2015;5:11869. doi: 10.1038/srep11869. PubMed PMID:

$60926158615 ;$ PMCID: 4497302.

610 34. Krucoff MO, Zhuang K, MacLeod D, Yin A, Byun YW, Manson RJ, Turner DA, Oliveira L, Lebedev

611 MA. A novel paraplegia model in awake behaving macaques. Journal of neurophysiology.

612 2017;118(3):1800-8. Epub 2017/07/14. doi: 10.1152/jn.00327.2017. PubMed PMID: 28701540; PMCID:

613 PMC5596146.

614

615

616

617

618

619

620

621

622

623

624

625

626

627 
629 We thank Gary Lehew for assistance with experimental setup, Tamara Phillips for assistance with

630 monkey handling, Paul Thompson for assistance with primate task software, Laura Oliveira and

631 Susan Halkiotis for technical assistance, and Joseph O'Doherty for comments on previous version

632 of manuscript. This research was supported by Duke Institute for Brain Sciences Germinator

633 Award and Duke Neurosurgery Research Support offered to Amol Yadav, NIH R25 awarded to

634 Max Krucoff, and Hartwell Foundation grant awarded to Miguel Nicolelis.

\section{Author Contributions}

637 A.P.Y., S.L., M.O.K., and M.A.L, designed experiments, A.P.Y. and S.L. performed rodent 638 experiments and surgeries, M.O.K and M.M.A performed primate surgeries, A.P.Y performed 639 primate experiments, A.P.Y. and S.L. analyzed data, A.P.Y. drafted manuscript, all authors edited 640 manuscript, M.A.L.N. supervised work.

\section{Competing financial interests}

643 The authors declare no competing financial or non-financial interests 


\section{Supplementary Information and Figures}

646 Primate implant surgery and timeline

647 Two weeks prior to surgery, the animal was acclimated to a protective vest. One day before 648 surgery, the animal's back was shaved with an electrical clipper under mild sedation. The day of 649 surgery, the animal underwent general anesthesia and endotracheal tube placement by staff veterinarians. The animal was then positioned prone on a radiolucent fluoroscopy table. The spine was placed into gentle flexion to open the interspinous spaces by placing the knees and pillows under the abdomen of the monkey. Pressure points were carefully padded. The surgical area was cleaned and prepped with $2 \%$ chlorhexidine gluconate and $70 \%$ isopropyl alcohol solution (ChloraPrepTM) and allowed to dry for 3 minutes. The surgical area was then draped in a sterile fashion. A dose of antibiotics was given within one hour prior to incision.

An anterior-posterior (AP) C-arm fluoroscopic x-ray was then taken to mark the level of the lowest rib, and the radiographic shadows of the spinous processes were positioned in the middle of the pedicles to ensure minimal rotation. After injecting a local anesthetic $(1.5 \%$ lidocaine with 1:100,000 epinephrine), a $2 \mathrm{~cm}$ incision was made at this location down to the fascia, and a selfretaining retractor was placed to hold the skin open. A trocar was then introduced through the the epidural space. Epidural location was confirmed using a loss of resistance technique, secured to the fascia using a 2-0 silk suture, and then a subcutaneous suprafascial pocket was created off midline to secure lead excess. A small hole was then created in the skin off midline to externalize the distal end of the lead. The same procedure was then repeated on the opposite 
670 site, ultimately positioning the electrodes next to one another in the midline dorsal epidural

671 thoracic space with a slight cranio-caudal offset (Supplementary Figure 1c).

672 Once both electrodes were externalized, the incision was closed with inverted dermal vicryl

673 sutures and a running 4-0 nylon suture. The incision was then covered with a thin layer of

674 bacitracin ointment, and piece of telfa was then placed over the incision and stapled to the skin.

675 Next, a custom plastic cap was sutured to the animal's skin with 3-0 nylon sutures to cover the

676 externalized leads (Supplementary Figure 1d). Such a cap allowed for access to the leads by the

677 researcher but protection from the animal. The telfa was removed 3 days after surgery. Surgical

678 sutures were removed 7-10 days after surgery. The sutures in the cap needed to be replaced

679 approximately monthly under sedation.

680 Monkey M's right lead stopped working a few days post-implant while the left lead stopped 681 working approximately 45 days post-implant. Hence the leads were explanted thereafter. Monkey

682 O's left lead stopped working a few days post-implant while the right lead worked for 135 days 683 after which they were extracted due to a skin infection at the externalization site. Monkey K's both

684 left and right leads were working until they were explanted approximately 150 days after surgery 685 due to a skin erosion at externalization site. 
bioRxiv preprint doi: https://doi.org/10.1101/2020.05.09.085647; this version posted September 23, 2020. The copyright holder for this preprint (which was not certified by peer review) is the author/funder, who has granted bioRxiv a license to display the preprint in perpetuity. It is made available under aCC-BY-NC-ND 4.0 International license.

\section{Supplementary Figure 1}

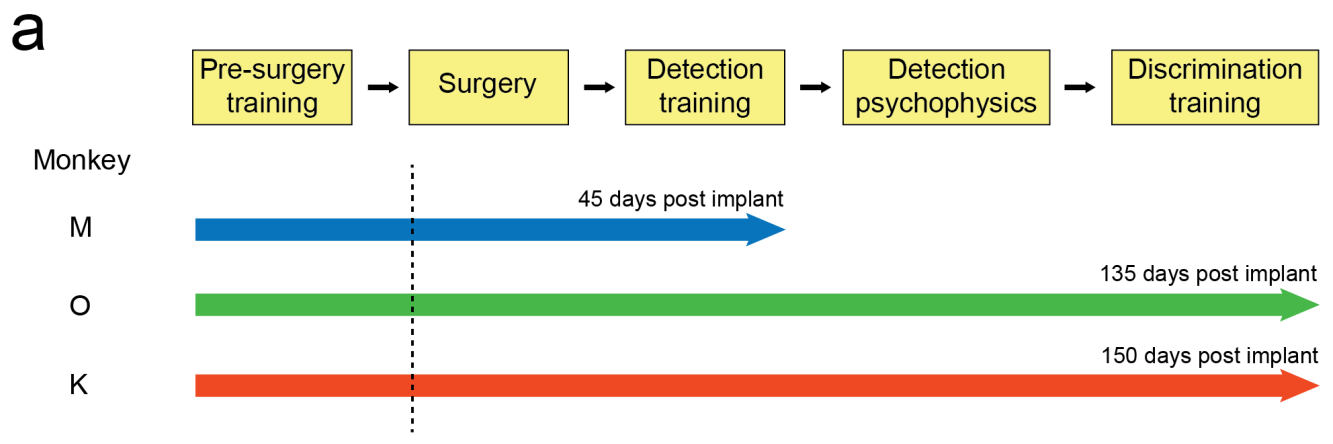

b

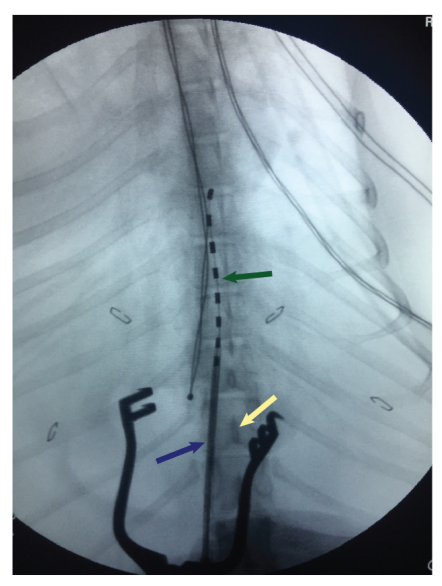

d

\section{C}
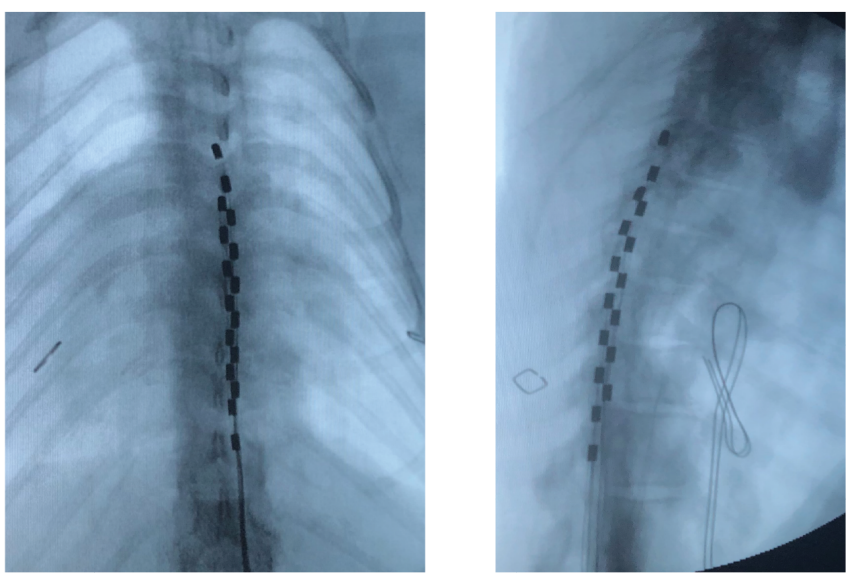
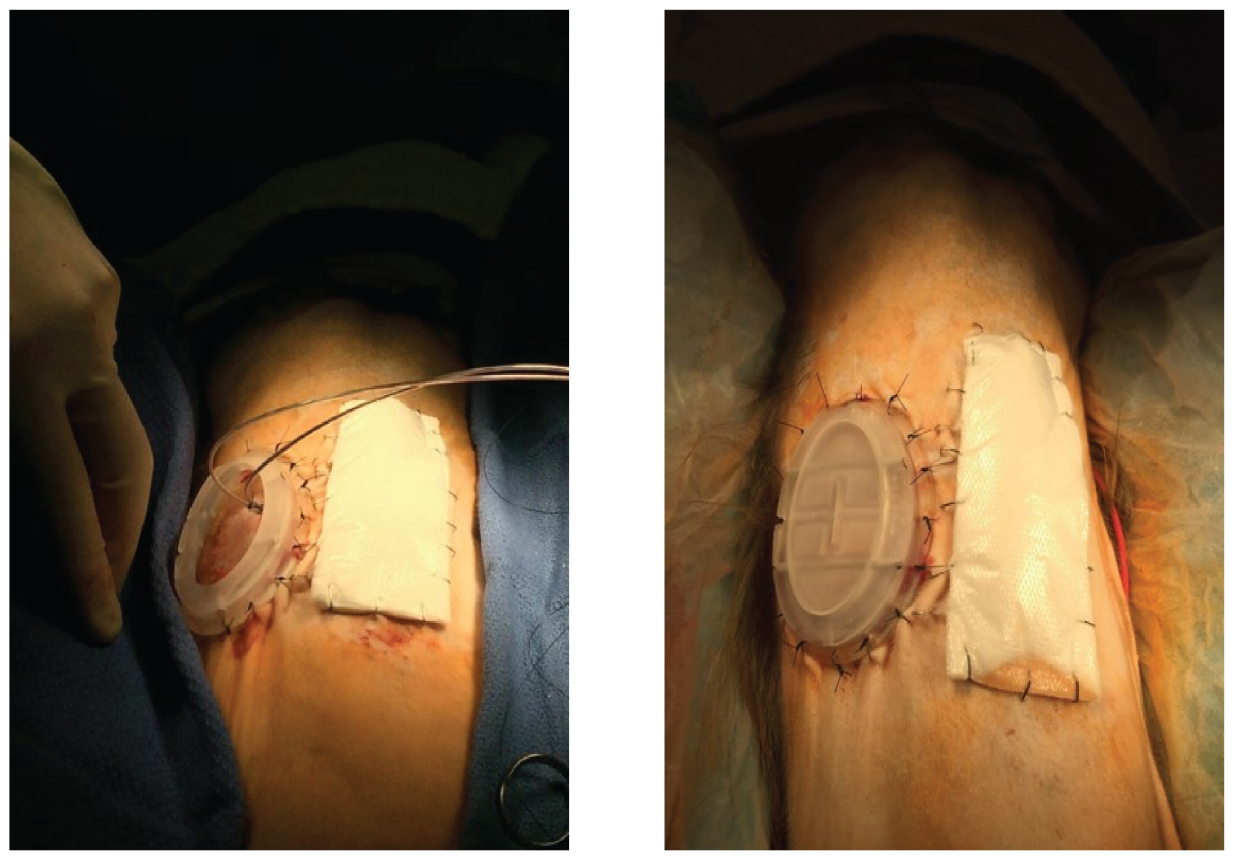
696 a) Monkeys were trained on the joystick task prior to spinal implant surgery. After they recovered from the 697 surgery behavioral training began for detection of SCS-based sensations. After that sensory detection 698 psychophysical experiments were performed followed by training on discrimination of SCS-based 699 sensations. Monkey M learned the SCS detection task, however, 45 days after surgery its implanted spinal 700 electrodes stopped working and hence were explanted. Spinal implants of Monkey $\mathrm{O}$ and $\mathrm{K}$ lasted until 701 they both were trained on the SCS sensory discrimination task. However, 135 and 150 days after surgery 702 for both monkeys the implants stopped working and were subsequently explanted. b) Anterior-posterior 703 (AP) fluoroscopic x-ray showing the introduction of the 8-contact cylindrical lead through the trocar into the 704 mid-thoracic dorsal epidural space. Blue arrow: trocar, Green arrow: 8-contact electrode array, Orange 705 arrow: spinous process. c) Final AP (left) and lateral (right) x-rays showing placement of dorsal mid-thoracic epidural electrodes with slight cranio-caudal offset. d) Externalized electrodes with custom plastic cap

707 sutured to the skin, and incision temporarily covered with telfa stapled to the skin. Cap open (left), cap 708 closed (right). 


\section{Supplementary Figure 2:}

a

Pulse width variation

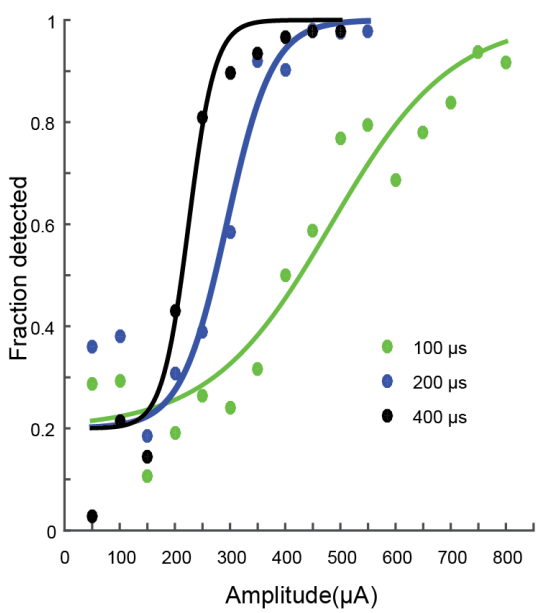

b

Monkey O

Frequency variation

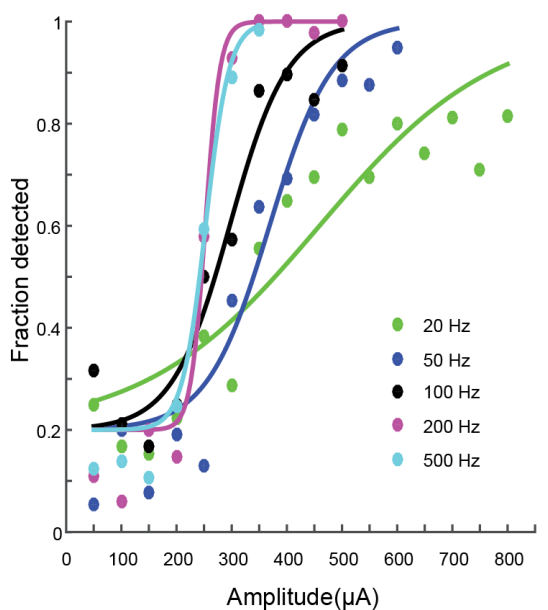

C

Duration variation

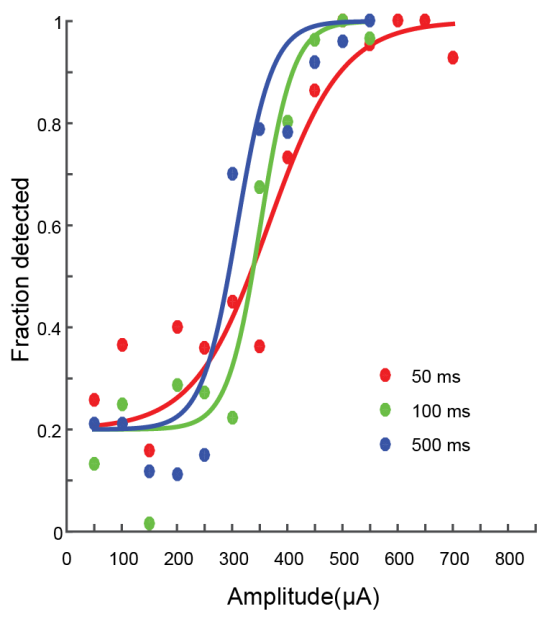

722 (frequency: $100 \mathrm{~Hz}$, pulse width: $200 \mu \mathrm{s}$, duration: $1 \mathrm{sec}$ ), we allocated different blocks of sessions where

723 (pulse width \& amplitude; panel 'a' ); (frequency \& amplitude; panel 'b'); and (duration \& amplitude; panel 


\section{Supplementary Figure 3}

a

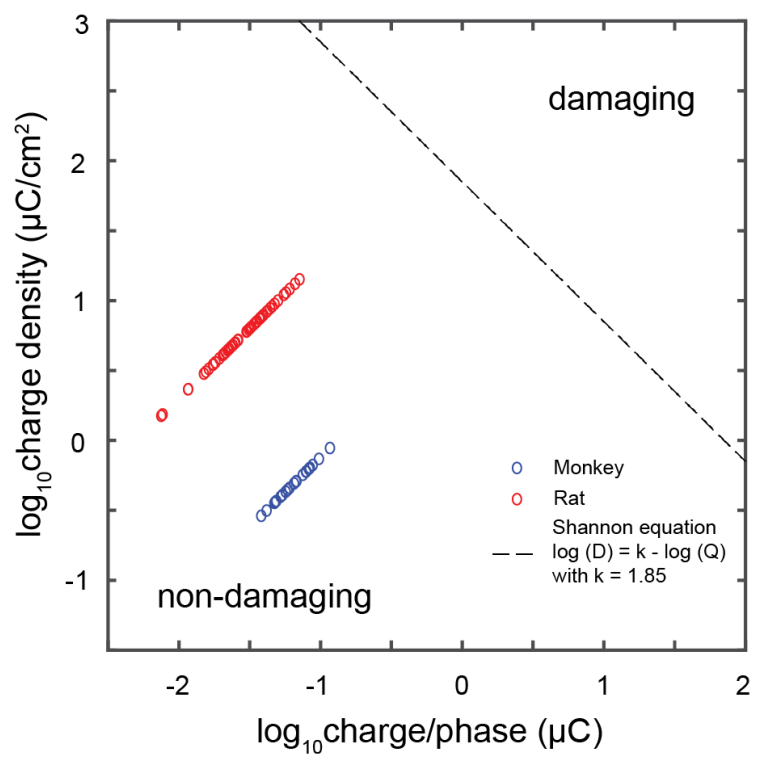

b

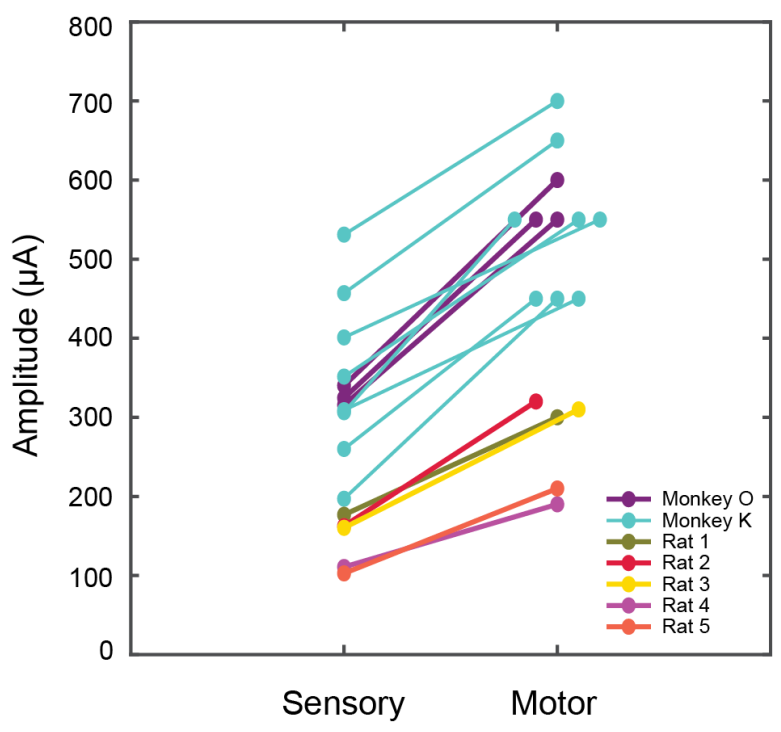

734

735

736

737

738

739

740

741

742

743

744

745

746

747

Supplementary Figure 3: Charge versus charge density and sensory versus motor thresholds. a) Sensory thresholds for monkeys (blue circles) and rats (red circles) determined by psychophysical evaluation at multiple stimulation parameters of pulse-width, frequency, and duration were below tissue damaging levels. Black dotted line indicates boundary between damaging and non-damaging stimulation defined by $\mathrm{k}=1.85$ in the Shannon equation $[\log (D)=k-\log (Q)]$ on a log charge density $(D)$ versus log charge per phase (Q) plot. b) Sensory thresholds were considerably lower than the amplitude levels where muscle twitches or skin fluctuations were observed on the animals' body. Purple and turquoise circles represent multiple electrode pairs tested in monkeys $\mathrm{O}$ and $\mathrm{K}$ respectively. 


\section{Supplementary Figure 4}

a

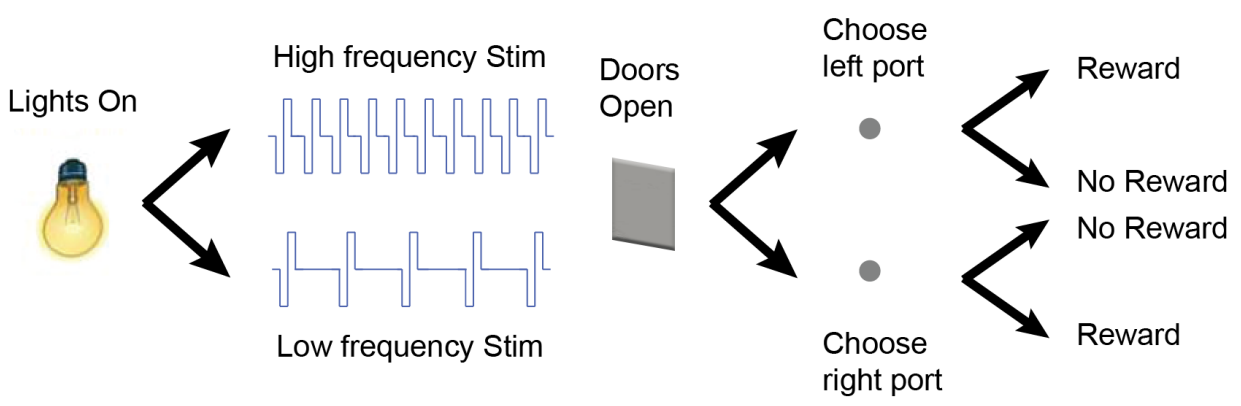

b

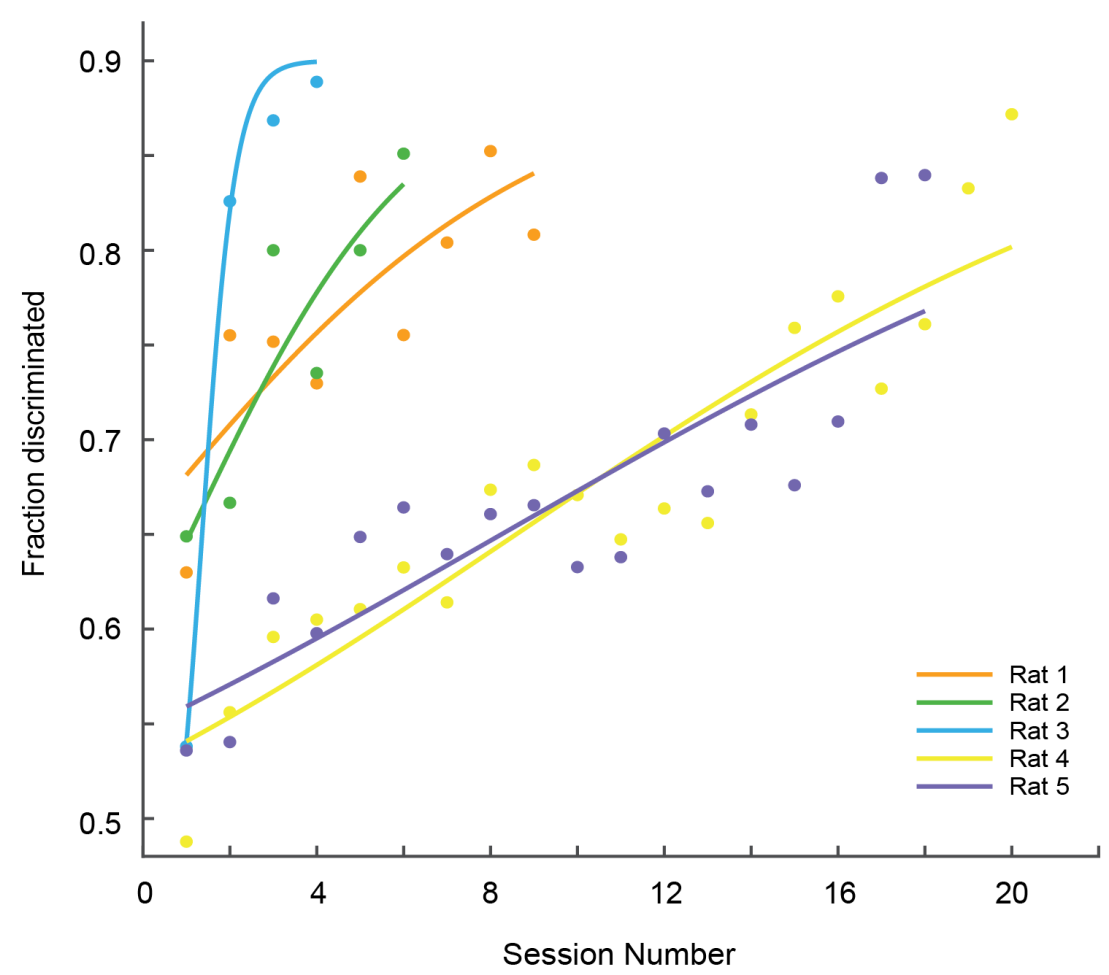

750 Supplementary Figure 4: Rats learned to discriminate SCS stimuli varying in frequency. a) Behavioral setup

751 for frequency discrimination task. Rats had to choose left reward port for higher frequency of SCS and right

752 reward port for lower frequency of stimulation. Stimulation was delivered at a constant amplitude at the

753 standard parameters (pulse width: $200 \mu \mathrm{s}$, duration: $1 \mathrm{sec}$ ) and rats had to choose the correct reward port

754 associated with each frequency to obtain water reward. b) Learning curves for five rats that learned to 755 discriminate two frequencies $(10 \mathrm{~Hz}$ vs $100 \mathrm{~Hz})$. Curves indicate sigmoidal fits to fraction of trials that were successfully discriminated as a function of session number. 


\section{Supplementary Table 1}

\begin{tabular}{|l|l|l|l|l|}
\hline Animal & Amplitude & Pulse Width & Frequency & Duration \\
\hline Monkey O & $50-800 \mu \mathrm{A}, 50 \mu \mathrm{A}$ step & $100-400 \mu \mathrm{s}$ & $20-500 \mathrm{~Hz}$ & $50-500 \mathrm{~ms}$ \\
\hline Monkey K & $50-800 \mu \mathrm{A}, 50 \mu \mathrm{A}$ step & $50-400 \mu \mathrm{s}$ & $10-500 \mathrm{~Hz}$ & $50-1000 \mathrm{~ms}$ \\
\hline Rat 1 & $50-325 \mu \mathrm{A}, 25 \mu \mathrm{A}$ step & $50-400 \mu \mathrm{s}$ & $10-500 \mathrm{~Hz}$ & $50-1000 \mathrm{~ms}$ \\
\hline Rat 2 & $50-325 \mu \mathrm{A}, 25 \mu \mathrm{A}$ step & $50-400 \mu \mathrm{s}$ & $10-500 \mathrm{~Hz}$ & $50-1000 \mathrm{~ms}$ \\
\hline Rat 3 & $50-325 \mu \mathrm{A}, 25 \mu \mathrm{A}$ step & $50-400 \mu \mathrm{s}$ & $10-500 \mathrm{~Hz}$ & $50-1000 \mathrm{~ms}$ \\
\hline Rat 4 & $50-187.5 \mu \mathrm{A}, 12.5 \mu \mathrm{A}$ step & $50-400 \mu \mathrm{s}$ & $10-500 \mathrm{~Hz}$ & $50-1000 \mathrm{~ms}$ \\
\hline Rat 5 & $50-175 \mu \mathrm{A}, 12.5 \mu \mathrm{A}$ step & $50-400 \mu \mathrm{s}$ & $10-500 \mathrm{~Hz}$ & $50-1000 \mathrm{~ms}$ \\
\hline
\end{tabular}

758

sensory detection. Animals were initially trained to detect SCS stimuli at standard stimulation parameters - frequency: $100 \mathrm{~Hz}$, pulse-width: $200 \mu \mathrm{s}$, and duration: $1000 \mathrm{~ms}$ ) as shown in Figures

2a and 4c. After that sensory thresholds were determined by using stimulation settings shown above. In blocks of consecutive sessions, amplitude and frequency or amplitude and pulse-width or amplitude and duration of stimulation were varied while keeping other parameters constant. In additional block of sessions in monkey $\mathrm{K}$, frequency $(10-1000 \mathrm{~Hz})$ and duration $(1-2000 \mathrm{~ms})$ $200 \mu \mathrm{s}$ and $325 \mu \mathrm{A}$ respectively. 